\title{
əEurasian Cooling Linked with Arctic Warming: Insights from PV Dynamics
}

\author{
YONGKUN XIE \\ State Key Laboratory of Numerical Modeling for Atmospheric Sciences and Geophysical Fluid Dynamics (LASG), Institute \\ of Atmospheric Physics, Chinese Academy of Sciences, Beijing, China \\ GUOXIONG WU AND YIMIN LIU \\ State Key Laboratory of Numerical Modeling for Atmospheric Sciences and Geophysical Fluid Dynamics (LASG), Institute \\ of Atmospheric Physics, Chinese Academy of Sciences, and College of Earth and Planetary Sciences, University of Chinese \\ Academy of Sciences, Beijing, China

\section{JIANPING HUANG} \\ Key Laboratory for Semi-Arid Climate Change of the Ministry of Education, College of Atmospheric Sciences, Lanzhou \\ University, Lanzhou, China
}

(Manuscript received 21 February 2019, in final form 30 December 2019)

\begin{abstract}
The three-dimensional connections between Eurasian cooling and Arctic warming since 1979 were investigated using potential vorticity (PV) dynamics. We found that Eurasian cooling can be regulated by Arctic warming through PV adaptation and PV advection. Here, PV adaptation refers to the adaptation of PV to forcing and coherent dynamic-thermodynamic adaptation to PV change. In a PV perspective, first, the anticyclonic circulation change over the Arctic is produced by a negative PV change through PV adaptation, in which the change means the linear trend from 1979 to 2017 . The negative PV change is directly regulated by Arctic warming because the vertical structure of Arctic warming is stronger at lower levels, which generates a negative PV change through the diabatic heating effect. Second, the circulation change produces a change in horizontal PV advection due to the existence of climatological PV gradients. Thus, as a balanced result, both the circulation change and PV change extend to the midlatitudes through horizontal PV advection and PV adaptation. Eventually, Eurasian cooling at the surface and in the lower troposphere is dominated by PV changes at the surface through PV adaptation. Meanwhile, enhanced Eurasian cooling in the middle troposphere is dominated by top-down influences of upper-level PV change through PV adaptation. Nevertheless, the upper-level PV changes are still contributed to by horizontal PV advection associated with Arctic warming. Overall, the general dynamics connecting Eurasian cooling with Arctic warming are demonstrated in a PV view.
\end{abstract}

\section{Introduction}

During the past several decades, amplified Arctic warming is one of the most remarkable phenomena regarding global temperature change (Stouffer and Manabe 2017; Xie et al. 2019). Meanwhile, remarkable regional cooling on decadal or multidecadal scales occurs in the context of overall global warming, such as the Eurasian

¿ Denotes content that is immediately available upon publication as open access.

Corresponding author: Guoxiong Wu, gxwu@lasg.iap.ac.cn cooling (Easterling and Wehner 2009; Cohen et al. 2014; Shepherd 2016). This kind of decadal variability is generally blamed for internal climate variability (Trenberth 2015; Steinman et al. 2015). On the one hand, the dominant role of internal climate variability associated with Atlantic and Pacific Oceans on multidecadal variability of temperature has been proposed by previous studies (Held 2013; Kosaka and Xie 2013; Steinman et al. 2015; Dai et al. 2015; Huang et al. 2017; Luo et al. 2017a). On the other hand, as directly observed in Fig. 1, Arctic warming is one of the strongest signatures during the past several decades (1979-2017), which overwhelms the signals of internal climate variability directly reflected by the temperature 

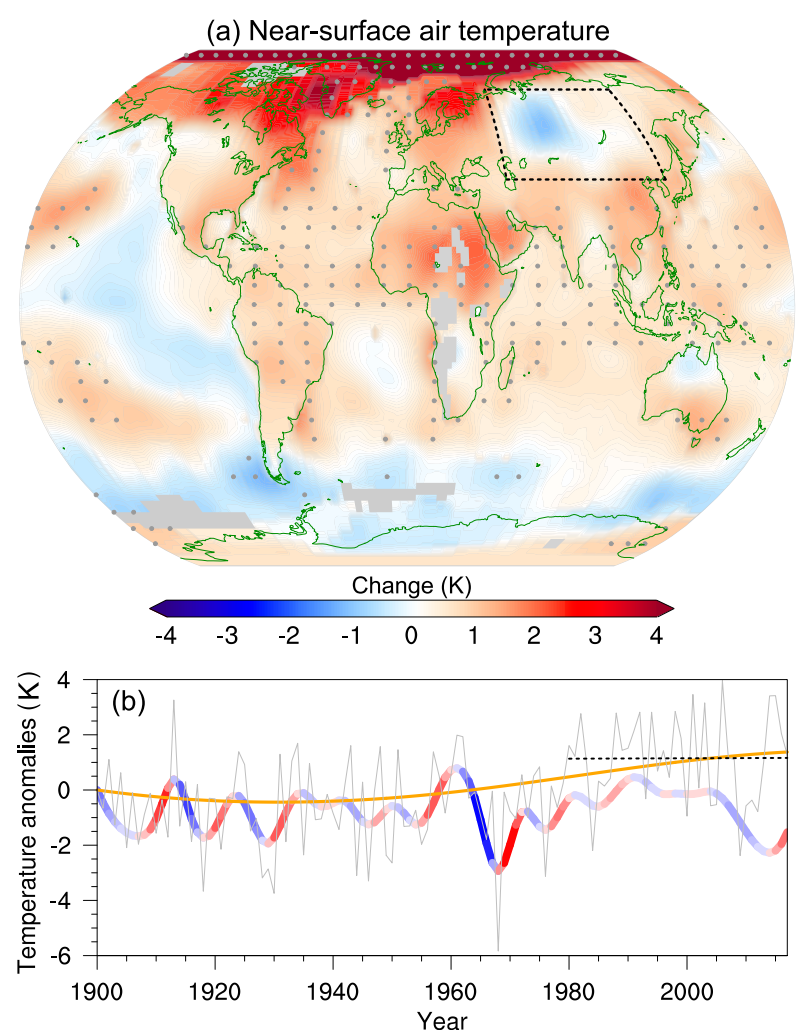

FIG. 1. (a) Near-surface air temperature change (K) (linear trend multiplied by the time span) for the period of 1979-2017 during boreal winter. The results are based on GISTEMP. The gray dots indicate that the linear trend is significant at the $99 \%$ confidence level based on a two-tailed Student's $t$ test. (b) Time series of nearsurface air temperature anomalies (relative to 1951-80) averaged over the region of $40^{\circ}-70^{\circ} \mathrm{N}, 50^{\circ}-130^{\circ} \mathrm{E}$, outlined by the rectangle in (a). The raw series is the gray line, and the orange line and the blue and red line indicate the long-term trend (IMF6 from EEMD) and decadal/multidecadal variability (sum of IMFs 3-5), respectively. The dashed black line indicates the trend line of the raw series from 1979 to 2017.

change over the Atlantic and Pacific Oceans. Recently, more and more studies have put their efforts into investigating the relative or joint effect of the warm Arctic and internal climate variability on the cold Eurasian pattern. Specific attention was paid to the internal climate variability of the upstream region (i.e., North Atlantic) (e.g., Luo et al. 2016, 2017a; Sung et al. 2018; Yang et al. 2018; B. Luo et al. 2019). An exact attribution relies on the model simulation such as the fingerprint method (Ding et al. 2019), while intermodel discrepancies make a robust attribution far from realizing (Cohen et al. 2018; Smith et al. 2019).

Apart from a full attribution, this paper focuses on the general dynamics that could link the Arctic warming with Eurasian cooling. Regarding dynamics, there are extensive works published. Here, a detailed review of all the previous works is not necessary because some excellent reviews are already available, such as those of Cohen et al. (2014, 2018), Overland et al. (2016), Coumou et al. (2018), and Screen et al. (2018). Previous works suggest many possible pathways linking the Arctic and the midlatitude. The main pathways include Rossby waves (Francis and Vavrus 2012; Sung et al. 2018; Li et al. 2019), meandering of the jet stream (Screen and Simmonds 2013, 2014; Francis and Vavrus 2015; Di Capua and Coumou 2016), the Arctic Oscillation (Yang et al. 2016), the North Atlantic Oscillation (Yang et al. 2018; B. Luo et al. 2019), polar vortices (Cohen et al. 2014), the Siberian high (Ye et al. 2018; Sung et al. 2018), atmospheric blocking (Yao et al. 2017; Luo et al. 2017b, 2018; B. Luo et al. 2019; D. Luo et al. 2019; Wegmann et al. 2018), stratospheric anomalies (Zhang et al. 2018), and eddy energy propagation (Gu et al. 2018).

Overall, more and more light is being shed on the dynamics of the Arctic and midlatitude linkages. As seen above, the complexity of the connections increased at the same time. And some pathways are tightly connected, such as the North Atlantic Oscillation and atmospheric blocking (Yang et al. 2018; B. Luo et al. 2019). Thus, this study examines the general dynamic and thermodynamic features of atmospheric circulation without preference as to the aforementioned specific pathways. To achieve this objective, we do the investigation using potential vorticity (PV) dynamics. We use PV dynamics because PV inherently depicts seamless coupling between dynamic and thermodynamic aspects (Ertel 1942; Yeh and Chu 1958; Charney and Stern 1962). In other words, any observed circulation and temperature change can, on a fundamental level, be attributed to PV. In this paper, piecewise PV inversion and the PV equation are used (Davis and Emanuel 1991; Hartley et al. 1998; Zhao et al. 2007; Egger 2008; Spengler and Egger 2012; Egger et al. 2017). Piecewise PV inversion (PPVI) quantitatively tells the effects of arbitrary PV change on the entire atmosphere, while the PV equation tells how the PV change occurred. Importantly, we show that PV inversion can also be used in the climate change realm, although it is commonly used in synoptic cases.

This paper focuses directly on the persistent change of the mean state from 1979 to 2017 rather than weather or interannual variability. The remainder of this paper is arranged as six parts. Section 2 describes all the data and methods used in this paper. Essential characteristics (e.g., the spatial pattern and vertical structure) of Eurasian cooling and Arctic warming are presented in section 3. Section 4 addresses the concept of PV adaptation based on the ideal case. Sections 5 and 6 address the vertical coupling among different levels and horizontal coupling among different locations, respectively. Concluding remarks are provided in section 7 . 


\section{Data and method}

\section{a. Reanalysis data}

ERA-Interim data are used in this study. The original model used to produce ERA-Interim data is an approximately $0.75^{\circ}$ grid (Dee et al. 2011), but the European Centre for Medium-Range Weather Forecasts (ECMWF) provides many choices of the resolution. Here, we choose a coarse-gridded output of $1.5^{\circ} \times 1.5^{\circ}$ at 37 pressure levels because the analysis of high-resolution 6-hourly data spanning 38 years (1979-2017) would be too cumbersome. A coarse-resolution output will not affect our results because the original model resolution did not change for even a coarse output and we do not investigate small-scale features. The climatology is the mean from 1979 to 2017, and the change from 1979 to 2017 is calculated as the linear trend for each variable multiplied by 39 years. In the following, the overbar (the form $\bar{A}$ ) represents the climatology, while the prime (the form $A^{\prime}$ ) indicates the change without specification. The boreal winter is defined as December to the following February.

\section{b. Piecewise PV inversion}

The essential idea of PPVI is analogous to the electric charge in the electric field (Hoskins et al. 1985; Hartley et al. 1998; Schneider et al. 2003; Egger and Spengler 2018). Here, PV corresponds to the electric charge, while temperature or circulation corresponds to properties of the electric field. The minimalist description of $\mathrm{PV}$ inversion is $\Phi=L^{-1}(q)$, where $\Phi$ and $q$ are the geopotential and pseudo- (or quasigeostrophic) PV (Charney and Stern 1962), respectively. The operator $L$ is a three-dimensional Laplacian-like operator, while $L^{-1}$ is the inverse operator. Notably, $L$ is an operator rather than a coefficient, which ensures that the threedimensional coupling among varied vertical levels and horizontal locations can be described by PV inversion more than just correspondence between $\Phi$ and $q$. The superposition principle of a linear operator $L$ allows piecewise $\mathrm{PV}$ inversion, namely, one-to-one correspondence of $\Phi_{n} \Phi_{n}$ and $q_{n}$ in $\sum_{1}^{n} \Phi_{n}=\sum_{1}^{n} L^{-1}\left(q_{n}\right)$ (Hartley et al. 1998).

In pressure $(p)$ coordinates, pseudo-PV is in the form

$$
q=f+\frac{1}{f_{0}} \nabla^{2} \Phi+\frac{\partial}{\partial p}\left(\frac{f_{0}}{\bar{S}} \frac{\partial \Phi}{\partial p}\right),
$$

where $f$ is the Coriolis parameter and $\nabla^{2}$ is a twodimensional Laplacian operator (Holton and Hakim 2013); $\bar{S}=-\bar{\alpha}(\partial \ln \bar{\theta} / \partial p)$ represents the static stability of the basic state and is only a function of pressure. Namely, the specific volume $\bar{\alpha}$ and potential temperature $\bar{\theta}$ are averaged over a large domain (northward of $10^{\circ} \mathrm{N}$ in this study). The $f$-plane assumption is adopted for relative vorticity. Namely, $f$ in the denominator of $(1 / f) \nabla^{2} \Phi$ is replaced by $f_{0}=2 \Omega \sin \left(\varphi_{0}\right)$, in which $\varphi=45^{\circ} \mathrm{N}$ and $\Omega=$ $7.292 \times 10^{-5} \mathrm{~s}^{-1}$ are Earth's angular speed of rotation. In this paper, $\mathrm{PPVI}$ is used to investigate change rather than the mean state. Here, the PV change is in the form

$$
\begin{aligned}
q^{\prime} & =\frac{1}{f_{0}} \nabla^{2} \Phi^{\prime}+\frac{\partial}{\partial p}\left(\frac{f_{0}}{\bar{S}} \frac{\partial \Phi^{\prime}}{\partial p}\right) \\
& =\frac{1}{f_{0}} \nabla^{2} \Phi^{\prime}+\frac{\partial}{\partial p}\left(\frac{f_{0}}{\bar{S}}\right) \frac{\partial \Phi^{\prime}}{\partial p}+\frac{f_{0}}{\bar{S}} \frac{\partial^{2} \Phi^{\prime}}{\partial p^{2}} .
\end{aligned}
$$

The technical details, such as step-by-step producer and boundary conditions, and the accuracy of PPVI producer are described in the appendix. Despite pseudo-PV, Ertel PV can also be inverted (Davis and Emanuel 1991). Nevertheless, pseudo-PV is adopted in this research because Ertel PV inversion is much more computationally intensive for a hemispheric domain and quasigeostrophic approximation is excellent for mesoscale systems. Hereafter, PV directly refers to pseudo-PV without specification.

\section{c. PV equation}

The PV equation is in the form

$$
\frac{d q}{d t}=-f_{0} \frac{\partial Q}{\partial p}+\mathbf{k} \cdot \nabla \times \mathbf{F},
$$

where $Q=\bar{\alpha} \dot{\theta} /(\bar{S} \bar{\theta})$ indicates the diabatic heating $(\dot{\theta}$ represents the material change rate of potential temperature), and $\mathbf{F}$ indicates the horizontal frictional force. The effect of friction is difficult to specifically evaluate from reanalysis data (Egger et al. 2015). Physically, friction tends to reduce the relative motion between two objects at an interface. Following Smagorinsky (1953) and Yeh and Chu (1958), the effect of boundary layer friction is approximated to be directly proportional to the vorticity perturbation. Specifically, the frictional term in the PV equation is expressed aswhere $\mathbf{k} \cdot \nabla \times \mathbf{F}=-\mu\left(1 / f_{0}\right) \nabla^{2} \Phi^{\prime}$, where $\mu$ is the positive frictional coefficient. Hence, it is clear that friction always tends to offset the change in PV. However, friction cannot alter the sign of PV change. Simply put, friction makes the eventual observed change more moderate than it would otherwise be. We do not further investigate friction in the following.

The Eulerian form PV equation without friction is

$$
\frac{\partial q}{\partial t}=-\mathbf{V}_{g} \cdot \nabla q-f_{0} \frac{\partial Q}{\partial p},
$$

where $\mathbf{V}_{g}$ is geostrophic wind. In a climate change sense, the equilibrium form should be adopted, namely, $-\mathbf{V}_{g} \cdot \nabla q-f_{0}(\partial Q / \partial p)=0$, by neglecting the local tendency 
term. Here, the linear perturbation form of the equilibrium PV equation is $-\left(\mathbf{V}_{g} \cdot \nabla q\right)^{\prime}-f_{0}\left(\partial Q^{\prime} / \partial p\right)=0$. By neglecting the high-order term, the PV equation in the perturbation form is finally

$$
-\mathbf{V}_{g}^{\prime} \cdot \nabla \bar{q}-\overline{\mathbf{V}}_{g} \cdot \nabla q^{\prime}-f_{0} \frac{\partial Q^{\prime}}{\partial p}=0 .
$$

The perturbation expansion was applied to $\left(\mathbf{V}_{g} \cdot \nabla q\right)^{\prime}$ in Eq. (5). Namely, there is $(A B)^{\prime}=A B-\overline{A B}=A^{\prime} \bar{B}+$ $\bar{A} B^{\prime}+A^{\prime} B^{\prime} \approx A^{\prime} \bar{B}+\bar{A} B^{\prime}$ for $A=\bar{A}+A^{\prime}$ and $B=\bar{B}+B^{\prime}$ because $A^{\prime} B^{\prime}$ is negligible for the large-scale features of $\mathrm{PV}$ advection. Note that the overbar and prime have a different meaning with the traditional mean-eddy interaction formulations. Nevertheless, the effect of the eddy is inherently included in our results because all the results are calculated directly from 6-hourly data.

\section{d. Ensemble empirical mode decomposition}

Ensemble empirical mode decomposition (EEMD) is used to split the time series of a variable into different oscillatory components with intrinsic time scales $(\mathrm{Wu}$ et al. 2011; Ji et al. 2014). Following Huang et al. (2017), we obtain six intrinsic mode functions (IMFs). As shown in Fig. A2, IMFs 1 and 2 are annual to interannual variabilities, IMFs 3 to 5 are decadal to multidecadal variabilities, and IMF 6 is a long-term trend. Here, the detailed parameters and steps to perform EEMD follow Huang et al. (2017).

\section{e. Plumb flux}

Plumb flux is used to identify the wave train of the stationary Rossby wave. The method to calculate Plumb flux is the same as described in Plumb (1985), namely expression (7.1) in that paper. Here, the domain used to calculate the static stability, expression (7.2) therein, is northward of $10^{\circ} \mathrm{N}$.

\section{Appearance and structure of Eurasian cooling and Arctic warming}

As shown in Fig. 1, the most apparent feature of wintertime temperature change from 1979 to 2017 is the amplified Arctic warming, also known as Arctic amplification (Stouffer and Manabe 2017). Meanwhile, the contrasting characteristic is cooling to various degrees over many regions globally, especially Eurasian cooling in the midlatitude regions. To better understand the Eurasian cooling, a series of temperature evolution averaged over the area of $40^{\circ}-70^{\circ} \mathrm{N}, 50^{\circ}-130^{\circ} \mathrm{E}$ is shown in Fig. 1b. EEMD (see section 2d) is used to identify the variability of temperature on various time scales. First, the overall change is a rise in temperature, namely, long- term warming. Besides, large interannual variability is involved, which is common in the high latitudes due to large internal atmospheric circulation variability (Wallace et al. 2012). Meanwhile, the decadal variability is indeed remarkable. Such a large magnitude of decadal variability will accelerate or decelerate warming by favoring or offsetting long-term warming trends. Taken together, the Eurasian cooling is mainly associated with the observed downward-trending decadal variability. However, the underlying mechanisms of this downward-trending decadal variability in temperature from 1979 to 2017 need to be explored further.

To get a global view, the vertical structure of Eurasian cooling and Arctic warming is examined further. Figure 2 shows a vertical-latitudinal cross section of the changes in temperature and geopotential height averaged over $60^{\circ}-$ $120^{\circ} \mathrm{E}$. Eurasian cooling occurs not only at the surface but also throughout almost the entire troposphere (Fig. 2a). The strongest cooling in the troposphere presents at about $500 \mathrm{hPa}$. Meanwhile, the Arctic warming also occurs throughout the whole troposphere. The strongest Arctic warming occurs at the surface, which is also suggested by Screen and Simmonds (2010) and Cohen et al. (2014). There is also remarkable cooling or warming occurring in the stratosphere, and we will examine the stratospheric influences on troposphere in section 5 .

Under geostrophic approximation, circulation could be represented by geopotential height in pressure coordinates. In pressure coordinates, the hydrostatic relation is $\partial \Phi / \partial p=-(R / p) T$, and the relation is applicable for both the mean state and change in the pressure coordinates. Thus, the temperature change should be proportional to the vertical gradient of geopotential change at the arbitrary pressure level. The relation is confirmed by the results in Fig. 2. The results show that the absolute changes in the vertical gradient of geopotential are larger in areas where the absolute value of temperature changes is larger for the same pressure level. Thus, the tight connections between atmospheric circulation change and regional temperature change are evident.

\section{Concept of PV adaptation based on the ideal case}

In the PV view, the seamless dynamic and thermodynamic coupling are straightforwardly indicated by Eq. (2), in which any change in geopotential $\Phi^{\prime}$ could induce the changes in both circulation [represented by vorticity term $\left.\left(1 / f_{0}\right) \nabla^{2} \Phi^{\prime}\right]$ and temperature [represented by static stability term $(\partial / \partial p)\left[\left(f_{0} / \bar{S}\right)\left(\partial \Phi^{\prime} / \partial p\right)\right]$ and supported by results shown in Fig. 2]. The classic Ertel PV conservation picture concisely and vividly depicts the 


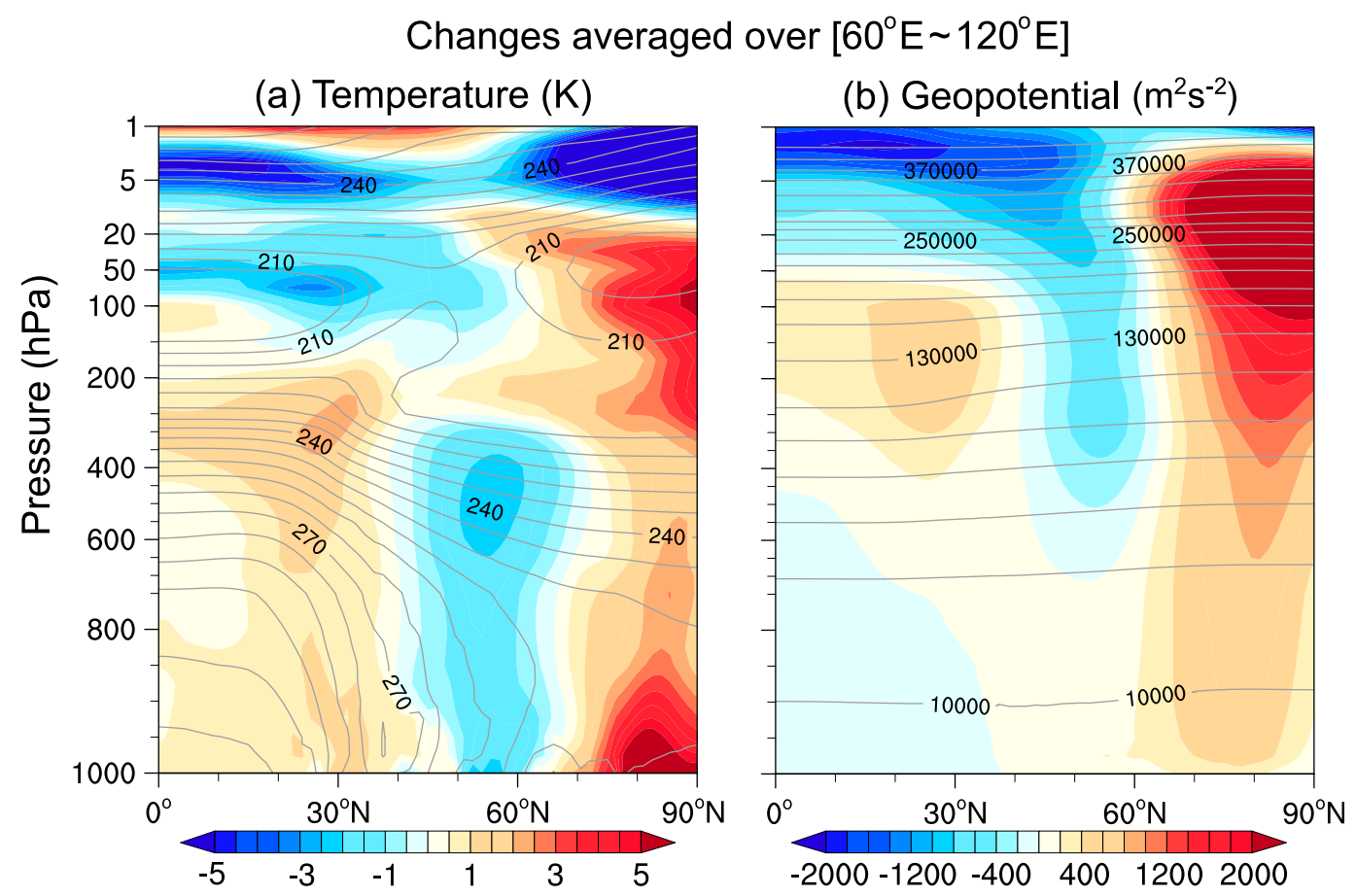

FIG. 2. (a) Vertical-latitudinal cross section of temperature changes (linear trend multiplied by the time span) for the period of $1979-2017$ averaged over the region of $60^{\circ}-120^{\circ} \mathrm{E}$ during boreal winter. The gray contour line indicates the corresponding climatology for the period of 1979-2017. (b) As in (a), but for geopotential.

inherent dynamic and thermodynamic coupling as shown in Fig. 3a. The corresponding pseudo-PV conservation picture is shown in Fig. 3b, which is similar to Fig. 3a but replacing the isentropic surface with the isobaric surface. $\mathrm{PV}$ conservation picture is shown in a Lagrangian view rather than an Eulerian view, which is generally adopted in climate change. In an Eulerian view, as indicated by Eq. (4), local PV conservation is very hard to satisfy because advection of PV widely exists and will change local $\mathrm{PV}$ even for the absence of diabatic heating and friction.

However, the picture of PV conservation still helps to get insights. Here, two ideal cases extended from the PV conservation picture are used for some instructive discussions. Two specific questions emerged when applying PV dynamic to climate change: 1) What is the effect of PV change? and 2) Why did the PV change? As already addressed in the introduction section, $\mathrm{PV}$ inversion and the PV equation can answer the two questions. However, a more fundamental question that has no direct help to solve the practical question but that helpful to conceptual understanding is this: "Why should the PV change?".

Here let us take the effect of diabatic heating in generating PV as an example, which has a simple mathematical expression as $\partial q / \partial t \propto-f_{0}(\partial Q / \partial p)$. Thus, diabatic heating generates positive, negative, and zero PV change when $Q$ is increased, decreased, or unchanged with height, respectively. Here, an ideal case extended from the PV conservation is shown in Fig. 3c. In this ideal case, at first, there is temperature change present at the surface. Then, the atmosphere strongly adapts to the surface temperature change so that the diabatic heating of atmosphere (induced by the surface temperature change and corresponding vertical motion of atmosphere) is even in the vertical direction (i.e., $\partial Q / \partial p=0$ ). In such a case, the surface temperature change induces no PV change, but geopotential greatly changes, and the balance relation is $\nabla^{2} \Phi^{\prime}=(\partial / \partial p)\left[\left(f_{0}^{2} / \bar{S}\right) \alpha^{\prime}\right]$ according to Eq. (2), where the hydrostatic relation, $\partial \Phi^{\prime} / \partial p=-\alpha^{\prime}$, is introduced.

In practice, the ideal case in Fig. $3 c$ can be quantified by using PPVI according to the superposition principle, which needs to keep only the change in surface thermal condition in the PPVI, as shown in Fig. 4b. The ideal case (Fig. 4b) with surface heating change but keeping a constant PV will make the geopotential change of atmosphere much stronger than the real case (Fig. 4a). In other words, changed PV in response to surface diabatic heating makes the change in motion of atmosphere more moderate. This conclusion also holds for the friction as demonstrated in section 2c. Therefore, PV change works as a stabilizer of the atmosphere in a fundamental understanding. This is an answer to "Why should the PV change?". 


\section{(a)}

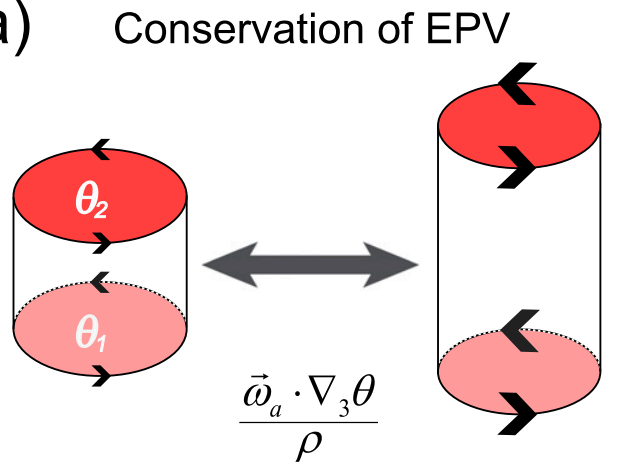

Constant PPV but anomalous
thermal condition at surface

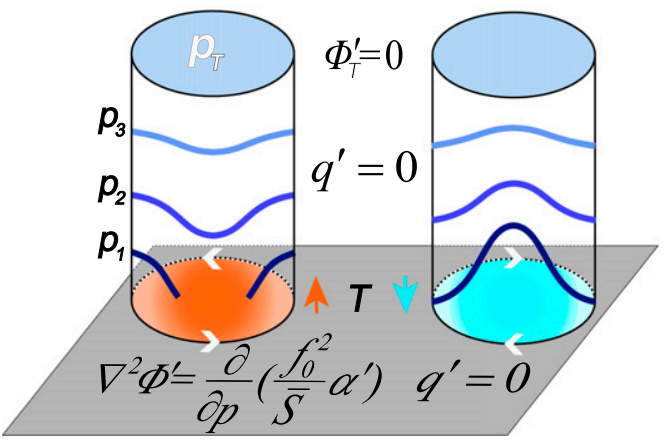

(b) Conservation of PPV
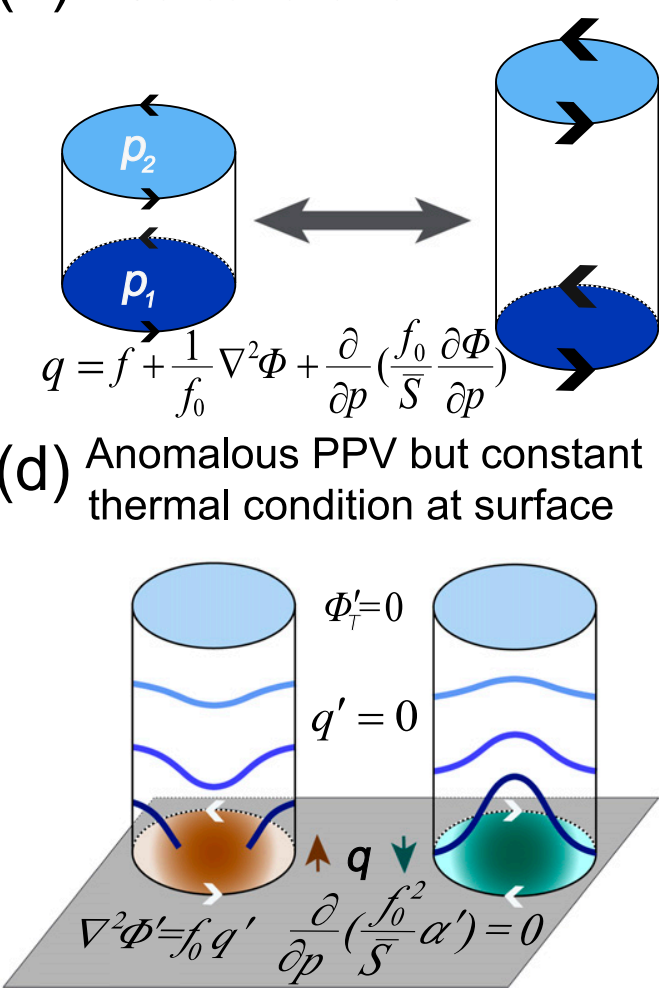

FIG. 3. Schematic views of (top) PV conservation for (a) EPV (Ertel PV) and (b) pseudo-PV (PPV) and (bottom) PV adaptation (c) under constant PPV but anomalous surface thermal conditions and (d) under anomalous PPV but constant surface thermal conditions. PV adaptation means the adaptation of PV (PV change) to forcing and coherent dynamic-thermodynamic adaptation to PV change. All the variables have the same meaning as described in section 2. Subscript $T$ indicates the top of the atmosphere. The gray parallelogram indicates Earth's surface. The visual illustration in (c) and (d) is similar to the traditional PV conservation illustration in (b) but with a fixed top and bottom.

Opposite to the ideal case in Fig. 3c, the other ideal case is shown in Fig. 3d, which prescribes a PV change at the surface but without surface thermal condition change $\left\{(\partial / \partial p)\left[\left(f_{0}^{2} / \bar{S}\right) \alpha^{\prime}\right]=0\right.$ rather than a zero temperature change\}. In Fig. 3d, the balance relation is $\nabla^{2} \Phi^{\prime}=f_{0} q^{\prime}$. Thus, geopotential must have a negative change in response to a positive PV change (according to $\Phi^{\prime} \propto-\nabla^{2} \Phi^{\prime}$ ), and vice versa. Regarding the ideal case in Fig. $3 c$, for surface warming stronger at the surface than above, $(\partial / \partial p)\left[\left(f_{0}^{2} / \bar{S}\right) \alpha^{\prime}\right]$ is positive under the current climatological $\bar{S}$. Therefore, geopotential change must be negative according to $\nabla^{2} \Phi^{\prime}=(\partial / \partial p)\left[\left(f_{0}^{2} / \bar{S}\right) \alpha^{\prime}\right]$, and vice versa.

The real case is the sum of Figs. 3c and 3d. Namely, for surface warming stronger at the surface than above, the balance in Fig. $3 \mathrm{c}$ tends to generate negative geopotential, while the stronger diabatic heating at the surface than above also induces negative PV, which tends to generate positive geopotential. Thus, the eventually observed geopotential change depends on the net effects after summing Figs. $3 \mathrm{c}$ and $3 \mathrm{~d}$ together. In other words, the reality is the sum of one rule "warming is cyclonic and cooling is anticyclonic" and another rule "a positive PV change is cyclonic and a negative PV change is anticyclonic." In short, from a "forcing" [i.e., diabatic heating and friction in Eq. (3)] to the final observed changes of atmosphere, two key adaptation processes are involved. One is the PV change as a direct adaptation to forcing [Eq. (3)]. The other is the commonly observed change of atmosphere (e.g., temperature and circulation) as an adaptation to PV change. Therefore, in brief, the adaptation of PV to forcing and coherent dynamic-thermodynamic adaptation to PV change is referred to as "PV adaptation." The nature of PV adaptation is the seamless dynamicthermodynamic coupling.

\section{Vertical coupling among different levels}

The previous section discusses the conceptual understanding of the "stabilizer" effect of PV change and introduces the concept of PV adaptation based on two ideal 
$500 \mathrm{hPa}$ geopotential change $\left(\mathrm{m}^{2} \mathrm{~s}^{-2}\right)$ due to
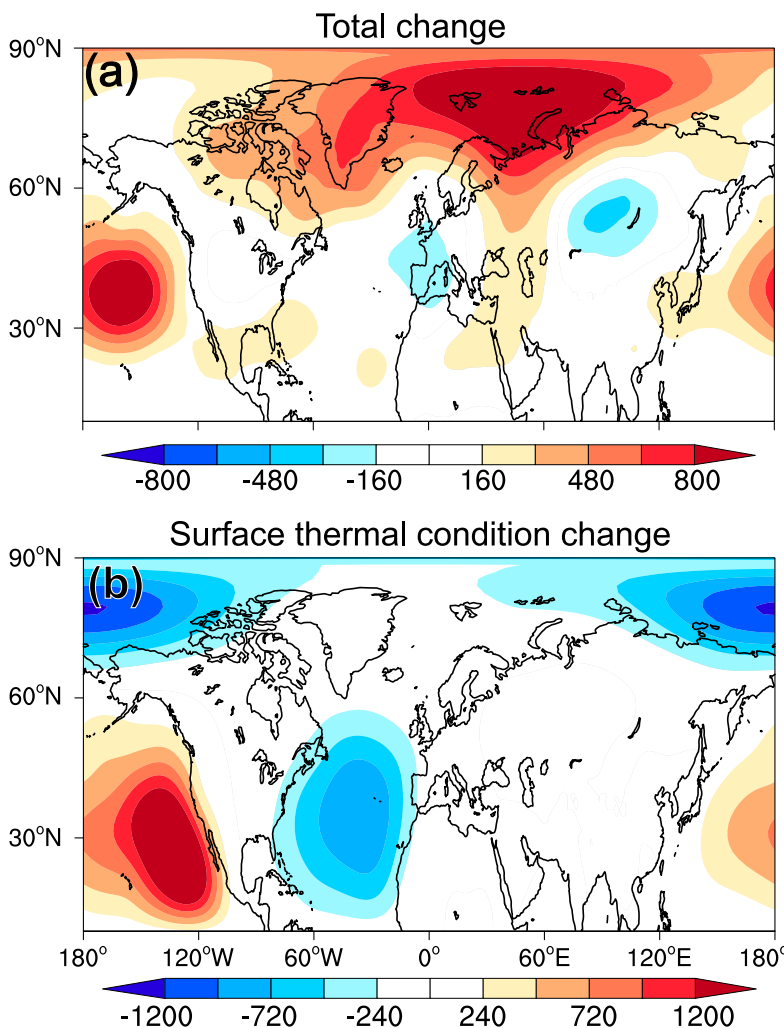

FIG. 4. Inverted geopotential changes $\left(\mathrm{m}^{2} \mathrm{~s}^{-2}\right.$ ) (linear trend multiplied by the time span) from PPVI with three pieces, at the 500-hPa level, during boreal winter from 1979 to 2017. The three pieces are (b) surface thermal condition change, surface and tropospheric PV change (not shown), and stratospheric total change (shown in Fig. 5f). (a) The sum of all the three pieces. Note that the ranges of the two color bars are different.

cases. In practice, the concept of PV adaptation can be quantified by using PPVI and further used to understand the vertical coupling between different levels. In a real case, the net influence of the surface on the atmosphere is determined by the surface total change (i.e., changes in both surface thermal condition and PV). Thus, a new three-piece PPVI scheme was performed based on this consideration. The three pieces are the surface total change, tropospheric PV change, and stratospheric total change.

Figure 5 shows the results of the new PPVI scheme. At $850 \mathrm{hPa}$, the geopotential change is dominated by surface total change (Fig. 5 left). The tropospheric PV change shows a tiny contribution to the geopotential change at $850 \mathrm{hPa}$ (Fig. 5c), and even the 850 -hPa level itself is located in the troposphere. The dominant surface contribution means that the change at $850 \mathrm{hPa}$ is determined by the surface PV change via PV adaptation.

In sharp contrast, both surface total change and tropospheric PV change have great influences on the geopotential change at $500 \mathrm{hPa}$ (Fig. 5 , right). The positive geopotential change at $500 \mathrm{hPa}$ corresponding to Arctic warming is determined by both surface total change and the tropospheric PV change. However, the negative geopotential change corresponding to Eurasian cooling (Figs. 1 and 2) is dominated by the tropospheric PV change (Fig. 5d), while surface total change shows negligible influence (Fig. 5b). The dominant contribution of tropospheric PV change means that enhanced Eurasian cooling at $500 \mathrm{hPa}$ is mainly determined by tropospheric PV change via $\mathrm{PV}$ adaptation.

In the new piecewise scheme, the tropospheric PV change piece covers a wide vertical range, which includes the 850- and 500-hPa target levels themselves. In this sense, we cannot determine the vertical coupling among different levels within the troposphere. To make the vertical coupling clearer, two additional schemes of PPVI with five pieces are performed. In the new piecewise schemes, the surface and stratospheric pieces are the same as those in Fig. 5, while the tropospheric PV change piece is divided into three pieces in two ways. Regarding the $850-\mathrm{hPa}$ level, the three pieces of tropospheric PV change are $900 \mathrm{hPa}$ and below, $875-825 \mathrm{hPa}$, and $800-250 \mathrm{hPa}$. Meanwhile, for $500-\mathrm{hPa}$ level, the three pieces are $600 \mathrm{hPa}$ and below, $550-450 \mathrm{hPa}$, and 400-250 hPa.

Figure 6 shows the results of the two new PPVI schemes. In Fig. 6, the two pieces $900 \mathrm{hPa}$ and below and 875-825 hPa are merged for the 850-hPa level (Fig. 6a). Similarly, the two pieces $600 \mathrm{hPa}$ and below and 550$450 \mathrm{hPa}$ are merged together for $500 \mathrm{hPa}$ (Fig. 6c). Because the contribution of the $900-\mathrm{hPa}$ and below piece (not shown) is very tiny relative to the other two pieces, so does the $600-\mathrm{hPa}$ and below piece (not shown). Thus, Figs. $6 \mathrm{a}$ and $6 \mathrm{c}$ represent the effects of a $\mathrm{PV}$ change within the vertical levels of 850 and $500 \mathrm{hPa}$, respectively. Meanwhile, the $800-250-\mathrm{hPa}$ and 400-250$\mathrm{hPa}$ pieces represent the influences from upper levels (relative to the 850- and 500-hPa levels, respectively). As shown in Fig. 6, the influences from the upper-level PV change are larger than those of local (vertical levels) PV change on geopotential change at both the 850- and $500-\mathrm{hPa}$ levels. Simply put, in the vertical direction, the influences of tropospheric PV change on both the 850and 500-hPa levels are mainly top-down.

Notably, the top-down influence of PV change on $850 \mathrm{hPa}$ (Fig. 6b) is negligible (relative to the bottom-up influence shown in Fig. 5a). In contrast, the top-down influence of $\mathrm{PV}$ change on the $500-\mathrm{hPa}$ geopotential change is as large as the influence of the surface total change (Figs. 5c and $6 \mathrm{~d}$ ). In particular, the negative geopotential change at $500 \mathrm{hPa}$ over the Eurasian cooling region is almost completely generated by the top-down influence of PV change. 

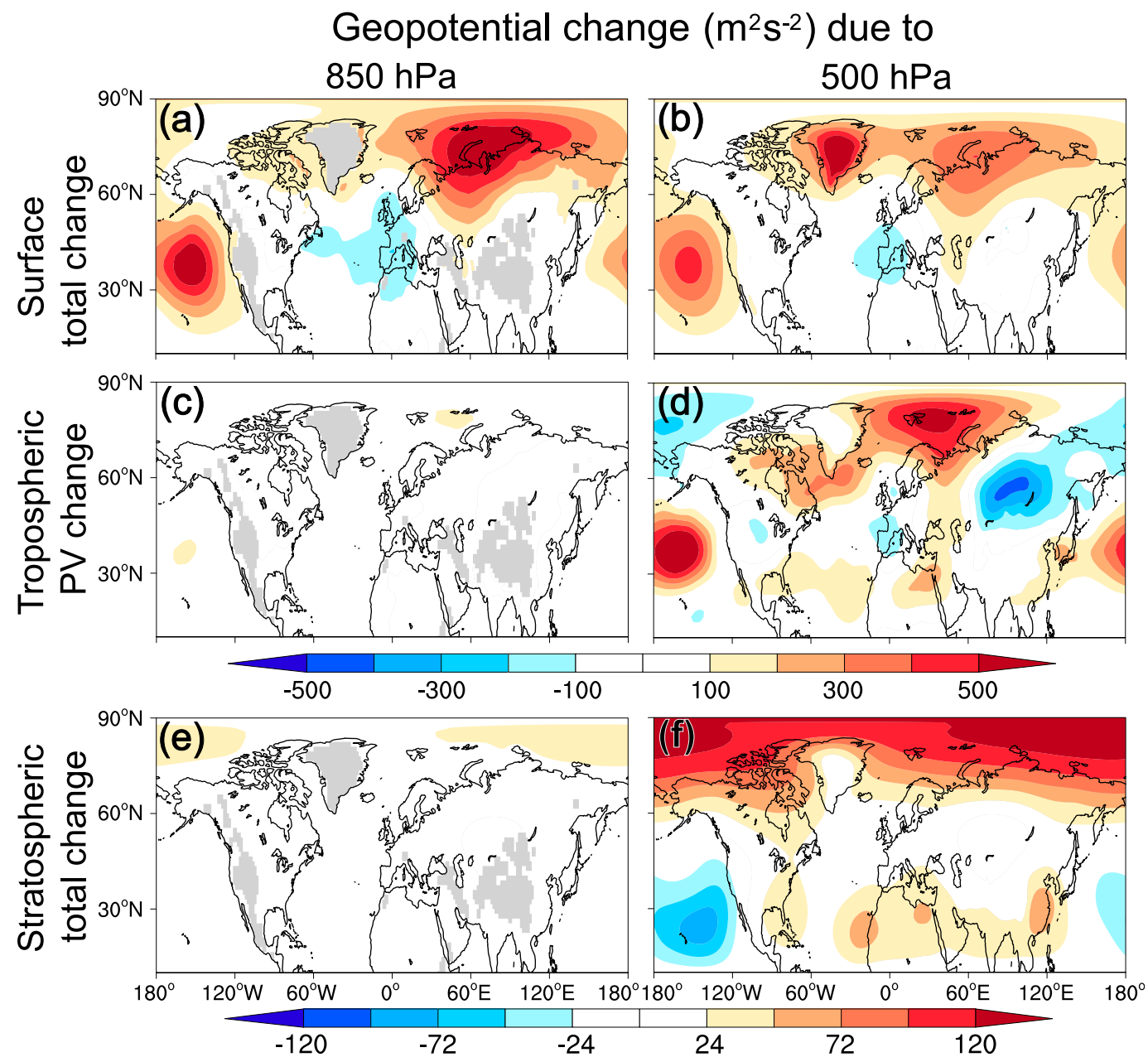

FIG. 5. Inverted geopotential changes $\left(\mathrm{m}^{2} \mathrm{~s}^{-2}\right.$ ) (linear trend multiplied by the time span) from PPVI with three pieces, at the (left) 850- and (right) 500-hPa levels, during the boreal winter from 1979 to 2017. The three pieces are (a),(b) surface total change, (c),(d) tropospheric PV change, and (e),(f) stratospheric total change. Note that the ranges of the two color bars are different.

Thus, enhanced Eurasian cooling at $500 \mathrm{hPa}$ is mainly determined by the top-down influence of PV change via PV adaptation. According to Figs. 5e and 5f, stratospheric total change show tiny direct influence on both the 850- and 500$\mathrm{hPa}$ levels. Nevertheless, the stratosphere may indirectly affect 850 and $500 \mathrm{hPa}$ via a top-down mechanism, such as a gradual influence through the upper troposphere to 500 and $850 \mathrm{hPa}$. Therefore, the effect of stratospheric total change on troposphere should be reexamined.

To do so, the stratospheric influence on the $250-\mathrm{hPa}$ level was examined, where the stratosphere is simply chosen as the range of $225-1 \mathrm{hPa}$. Figure 7 shows the geopotential change at $250 \mathrm{hPa}$ from three-piece PPVI, the same as that in Fig. 5. As shown in Fig. 7, stratospheric total change show very little influence on the $250-\mathrm{hPa}$ geopotential change relative to that of the tropospheric PV change. In addition, stratospheric influence mainly occurred over the Arctic rather than over the Eurasian cooling region (Fig. 7b). The stratospheric influence on tropospheric Eurasian cooling is negligible. Nevertheless, on the synoptic scale, the stratospheric influence on the troposphere may be crucial (Hartley et al. 1998; Cohen et al. 2014; Zhang et al. 2018). In summary, through PV adaptation, the bottom-up surface influence dominates the 850-hPa level, while both bottom-up surface and topdown upper-level (troposphere) influences control the 500-hPa level. However, enhanced Eurasian cooling at $500 \mathrm{hPa}$ is solely determined by the top-down influence.

\section{Horizontal coupling due to PV advection and adaptation}

In the last section, we explored the vertical coupling among different levels. However, the vertical coupling is 


\section{Geopotential change $\left(\mathrm{m}^{2} \mathrm{~s}^{-2}\right)$ due to PV change}
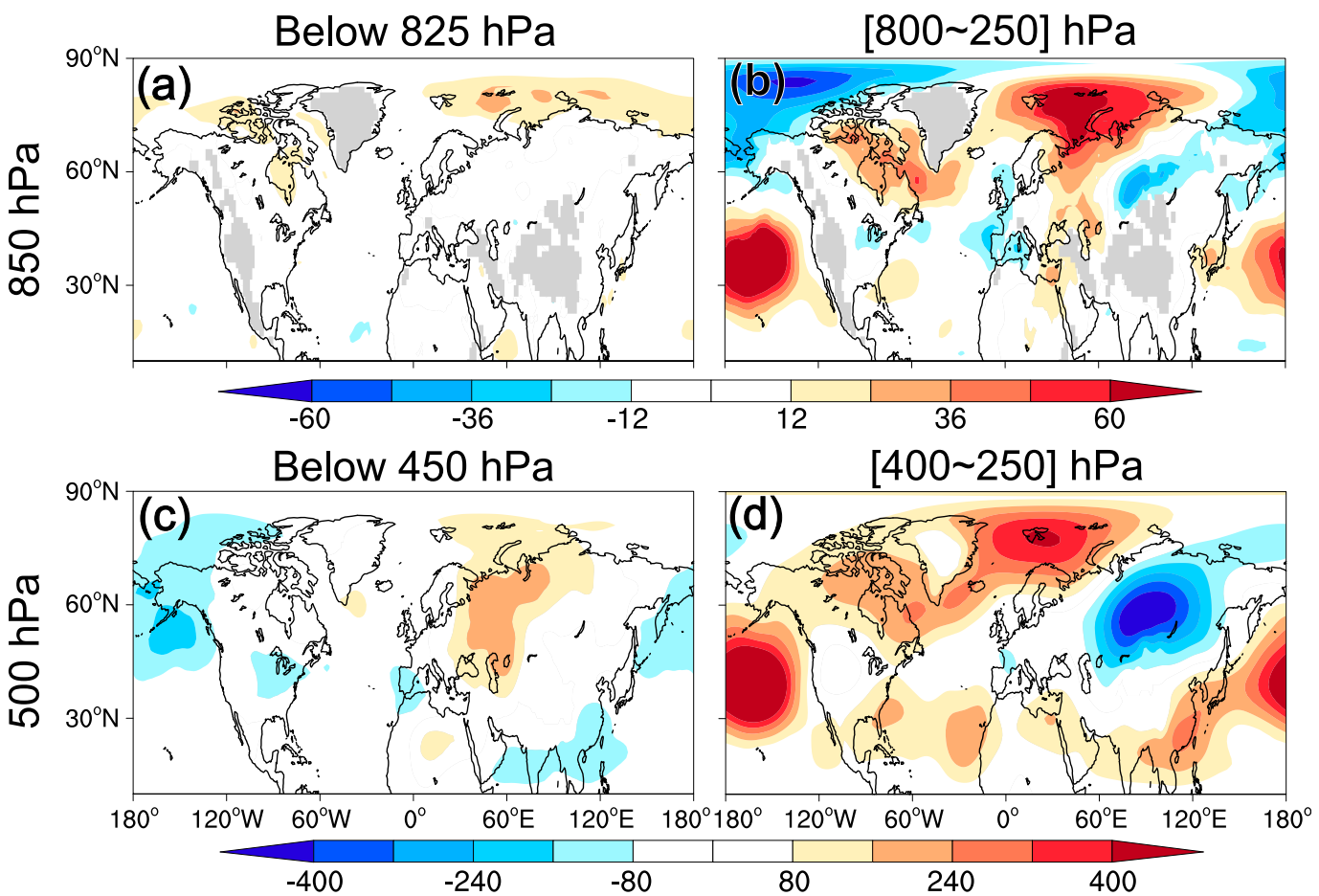

FIG. 6. Inverted geopotential changes $\left(\mathrm{m}^{2} \mathrm{~s}^{-2}\right)$ (linear trend multiplied by the time span) from PPVI with five pieces, at the (top) 850- and (bottom) 500-hPa levels, during the boreal winter from 1979 to 2017 . Two of the five pieces are surface and stratospheric total change. For $850 \mathrm{hPa}$, the remaining three pieces are tropospheric PV change from the surface to $900 \mathrm{hPa}, 875-825 \mathrm{hPa}$, and (b) $800-250 \mathrm{hPa}$. For $500 \mathrm{hPa}$, the remaining three pieces are tropospheric PV change from the surface to $600 \mathrm{hPa}, 550-450 \mathrm{hPa}$, and (d) $400-250 \mathrm{hPa}$. (a) The sum of two pieces (surface-900 $\mathrm{hPa}$ and $875-825 \mathrm{hPa}$ ) is shown, because the surface-900-hPa piece has a very small value. (c) As in (a), but the sum of two pieces is shown (surface-600 hPa and 550-450 hPa). Again, please notice the range of the color bar.

not enough to tell the whole story because the linkage between Eurasian cooling and Arctic warming must have a horizontal pathway. On the basis of vertical coupling, the horizontal coupling is explored. To access the horizontal coupling, we just need to determine whether the local PV change is contributed by horizontal PV advection.

Here, only horizontal PV advection at the levels 850 and $500 \mathrm{hPa}$ is examined because the changes show equivalent barotropic structure (Fig. 2). Regarding climate change, the horizontal $\mathrm{PV}$ advection term is linearized as $-\mathbf{V}_{g}^{\prime} \cdot \nabla \bar{q}-\overline{\mathbf{V}}_{g} \cdot \nabla q^{\prime}$ according to Eq. (5). The $\mathrm{PV}$ change itself in the equilibrium PV equation is directly reflected in the horizontal advection term. This is very different from the synoptic case, in which the PV change is reflected in the local tendency term $[\partial q / \partial t$ in Eq. (4)]. In terms of physical understanding, the nature of the difference between climate and the synoptic case is a complete or ongoing $\mathrm{PV}$ adaptation.

Figure 8 shows the PV climatology and change overlaid with the wind change and climatology for both
850 and $500 \mathrm{hPa}$. The combinations of wind change/PV climatology and wind climatology/PV change represent $-\overline{\mathbf{V}}_{g}^{\prime} \cdot \nabla \bar{q}$ and $-\overline{\mathbf{V}}_{g}^{\prime} \cdot \nabla q^{\prime}$, respectively. As shown in Fig. 8a, over the Eurasian cooling-Arctic warming region, the wind change flows across the isoline of climatological PV (with a large crossing angle). Thus, PV advection via wind change/PV climatology is vital. The situation at $500 \mathrm{hPa}$ is similar (Fig. 8c).

Now, physical understanding of the relationship between horizontal PV advection change and PV change itself is a key to move forward. To make things clearer, we first examine an ideal case. According to Eq. (5), the balance relation is $-\mathbf{V}_{g}^{\prime} \cdot \nabla \bar{q}+\overline{\mathbf{V}}_{g} \cdot \nabla q^{\prime}=0$ when diabatic heating and friction are neglected. The situation at $500 \mathrm{hPa}$ is closer to this ideal case than that at $850 \mathrm{hPa}$. Therefore, we use the featured values of wind and $\mathrm{PV}$ at $500 \mathrm{hPa}$. Symbolically, the domain is chosen as $0^{\circ}-60^{\circ} \mathrm{E}$, $40^{\circ}-80^{\circ} \mathrm{N}$, and the magnitudes of the variables in both climatology and change are roughly set according to the featured values in Fig. 8 (bottom). For simplicity, the 


\section{$250 \mathrm{hPa}$ geopotential change $\left(\mathrm{m}^{2} \mathrm{~s}^{-2}\right)$ due to}

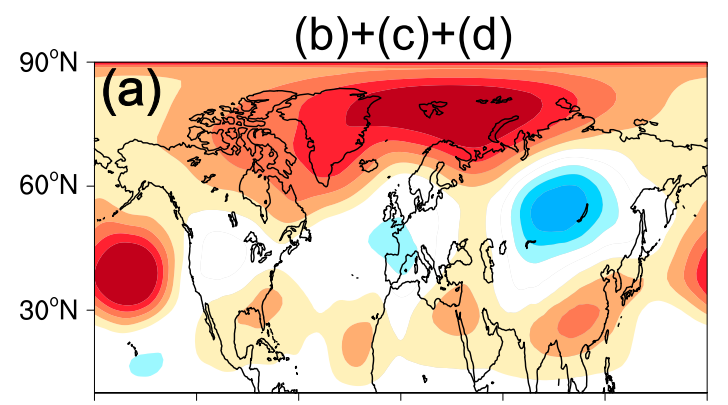
Stratospheric total change
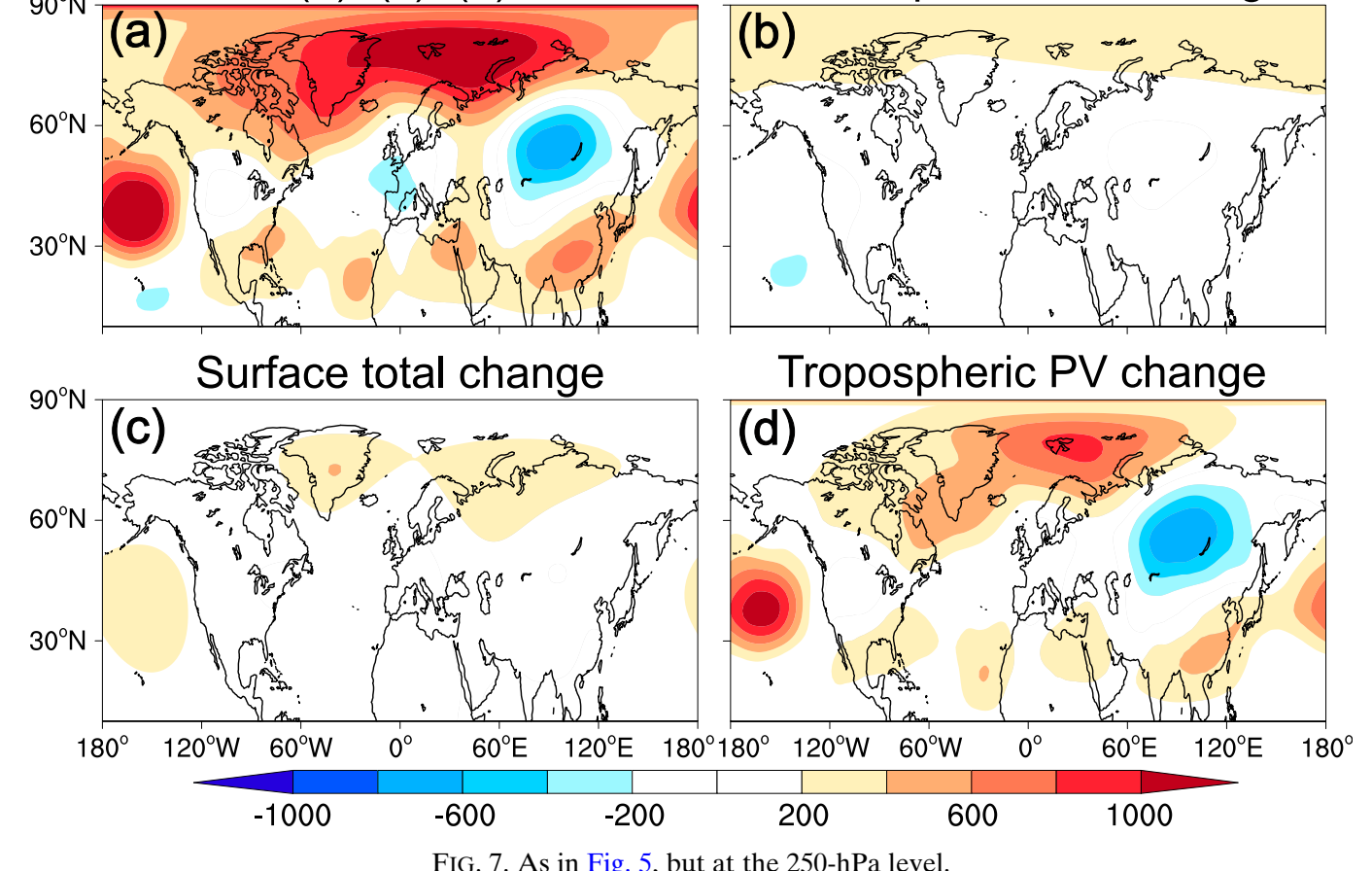

Tropospheric PV change

climatological wind is pure zonal (uniformly $12 \mathrm{~m} \mathrm{~s}^{-1}$ ), the wind change is pure meridional (with anticyclonic zonal shear of 5 to $-5 \mathrm{~m} \mathrm{~s}^{-1}$ from west to east, and northward is positive), and PV is zonally uniform but with a meridional gradient (1-8 $\times 10^{-5} \mathrm{~s}^{-1}$ from south to north). This ideal case is shown in Fig. 9 (top), in which the overall patterns do not change with, although the magnitudes will change with, different values of selected parameters.

Under the PV climatology in Fig. 9 (top left), the southward wind change has positive PV advection, whereas the opposite is true for the northward wind change. The PV advection change induced by $-\mathbf{V}_{g}^{\prime} \cdot \nabla \bar{q}$ for a given zonal shear value because of the wind change is shown in Fig. 9 (top center). Then, the term $-\overline{\mathbf{V}}_{g} \cdot \nabla q^{\prime}$ is balanced with $-\mathbf{V}_{g}^{\prime} \cdot \nabla \bar{q}$. After the balance relation is solved, the PV change is shown in Fig. 9 (top right), where the PV change at the western boundary is set as zero. The balance between $-\mathbf{V}_{g}^{\prime} \cdot \nabla \bar{q}$ and $-\overline{\mathbf{V}}_{g} \cdot \nabla q^{\prime}$ will eventually make the distribution of PV change induced by $-\mathbf{V}_{g}^{\prime} \cdot \nabla \bar{q}$ move downstream. Thus, the eventual PV change does not directly overlap with the PV advection change implied by the circulation change $\left(-\mathbf{V}_{g}^{\prime} \cdot \nabla \bar{q}\right)$.

With the help of the ideal case (Fig. 9, top), a real change at the $500-\mathrm{hPa}$ level is not difficult to understand (Figs. 8c,d). The phenomenon that occurred around the Eurasian cooling region (Figs. 8c,d) is similar to the ideal case (Fig. 9, top). PV advection induced by the wind change upstream of the Eurasian cooling region (Fig. 8c) was advected by the climatological wind downstream (Fig. 8d). Eventually, the horizontal PV advection change generated a positive PV change over the Eurasian cooling region and a negative PV change over the upstream regions (Fig. 8d). In contrast, the situation at $850 \mathrm{hPa}$ (Figs. 8a,b) seems different than that at $500 \mathrm{hPa}$ and in the ideal case (Figs. 8c,d and 9, top). This discrepancy is expected because the diabatic heating effect is essential in the lower troposphere. Nevertheless, the general concept that PV advection induced by the upstream wind change will be advected by the climatological wind to downstream, that is, the compensation between $-\mathbf{V}^{\prime} \cdot \nabla \bar{q}$ and $-\overline{\mathbf{V}}_{g} \cdot \nabla q^{\prime}$, exists independent of whether force exists.

In extratropical regions, it is inevitable for an anticyclonic (or cyclonic) circulation change to cross the isoline of climatological PV because large PV gradients are widespread over the extratropical regions (e.g., Figs. 8a,c). Therefore, the anticyclonic circulation change induced by Arctic warming will extend southward via horizontal PV advection and PV adaptation. The schematic view in Fig. 9 (bottom) shows the extension of the Arctic warminginduced anticyclonic circulation change. As shown in Fig. 9 (bottom right), first the local anticyclonic circulation change induced by Arctic warming advects positive PV to the adjacent area to the southeast and negative PV to the adjacent area to the southwest. No PV advection is 


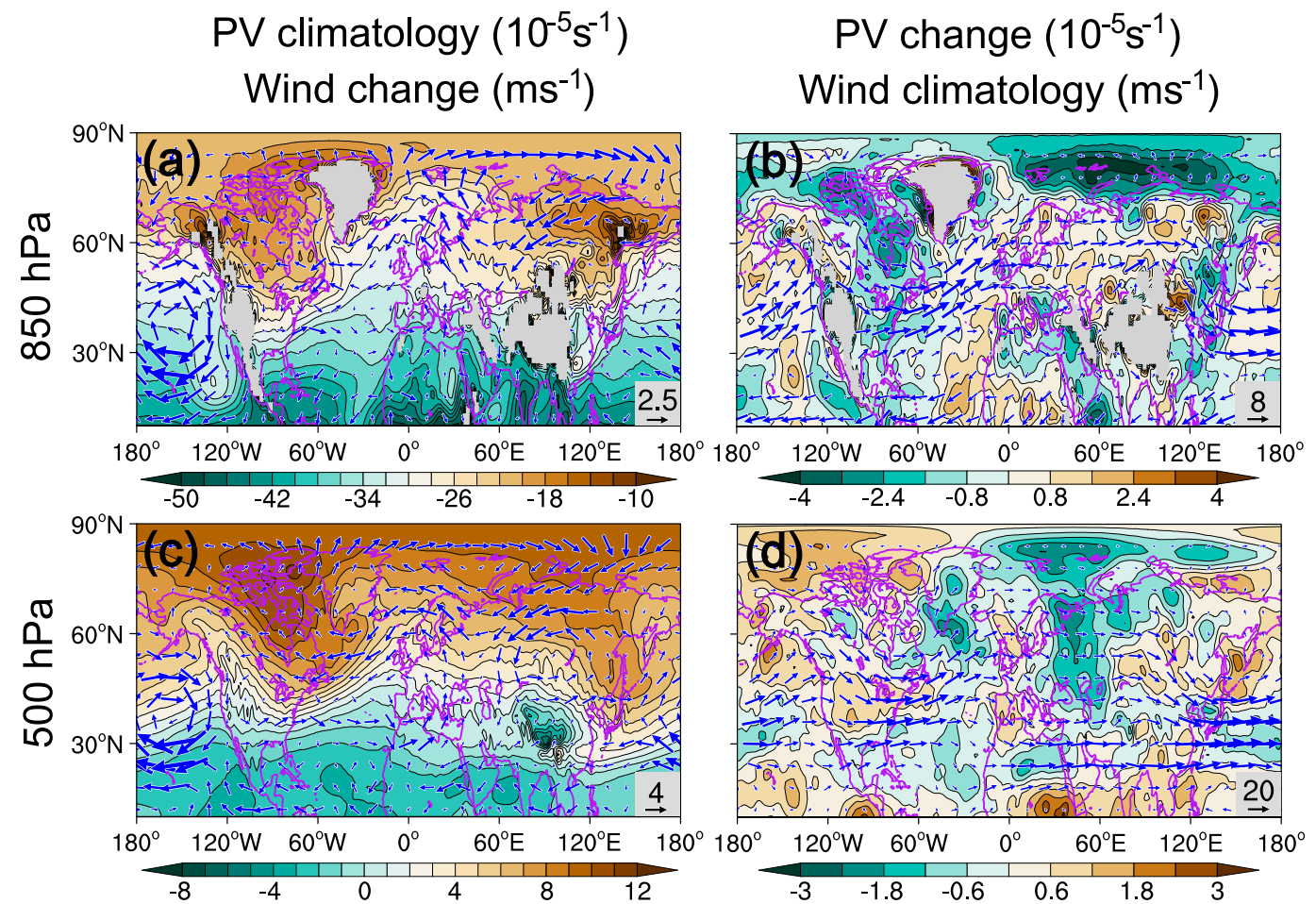

FIG. 8. (a),(c) PV climatology (filled; $10^{-5} \mathrm{~s}^{-1}$ ) and horizontal wind change (vectors; linear trend multiplied by the time span; $\mathrm{m} \mathrm{s}^{-1}$ ) during the boreal winter from 1979 to 2017. (b),(d) As in (a) and (b), but for PV change and horizontal wind climatology. Results are shown at the (top) 850- and (bottom) 500-hPa levels.

shown on the northern side of the anticyclonic circulation anomaly (Fig. 9, bottom) because the PV gradient is very small in very northern regions (Figs. 8a,c). Second, the PV change induced by meridional wind advection is advected by climatological wind downstream. As shown in Fig. 9 (top), after a temporal balance between meridional and zonal PV advection is achieved, the negative PV change on the southern side of the anticyclonic anomaly is enhanced. In turn, the enhanced PV change induces a northward extension of the anticyclonic circulation anomaly via $\mathrm{PV}$ adaptation. At the same time, $\mathrm{PV}$ advection by climatological wind induces positive PV change in the downstream regions (east of the anticyclonic circulation anomaly). The final balanced PV change is schematically shown in Fig. 9 (bottom right).

The illustration of the horizontal PV advection at $500 \mathrm{hPa}$ (Fig. 8, bottom) is identical to the schematic view in Fig. 9 (bottom). In Fig. 8 (bottom), the negative PV change in the Arctic Ocean induced by Arctic warming, the northward extension of this negative PV change, and the positive PV change over the downstream Eurasian cooling region are all observed. As demonstrated in the last section, Eurasian cooling at $500 \mathrm{hPa}$ is dominated by top-down influence. The situation of horizontal PV advection at levels higher than
$500 \mathrm{hPa}$ is similar to that at $500 \mathrm{hPa}$. Simply put, enhanced Eurasian cooling at $500 \mathrm{hPa}$ is regulated by both horizontal coupling (with Arctic warming) at higher levels and top-down vertical coupling.

Based on the PV advection perspective, the horizontal coupling is further examined using PPVI. Figure 10 shows the results of a new PPVI scheme based on geographical piecewise. In the new scheme, there are three horizontal pieces, including $70^{\circ}-90^{\circ} \mathrm{N}, 30^{\circ}-70^{\circ} \mathrm{N}$, and $10^{\circ}-30^{\circ} \mathrm{N}$. For each piece, the total change (changes in the thermal condition at the bottom and top boundaries and the PV for the entire atmosphere) is set to the observed values within the piece and is set to zero outside of each of the pieces. As shown in Fig. 10, the total change within each horizontal piece present evident influences on the circulation out of the piece. As shown in Fig. 10a, Arctic warming-related total change generates a clear influence on the circulation change over the adjacent area to the south (Europe). Similarly, total change over the midlatitude domain of $30^{\circ}-70^{\circ} \mathrm{N}$ also has a clear influence on adjacent regions (Fig. 10b). The extended influences shown in Fig. 10 confirm the extension process of the PV change schematically shown in Fig. 9 (bottom). Specifically, Fig. 10 suggests that the local PV change can further advect PV 


\section{Horizontal PV advection at $500 \mathrm{hPa}$}
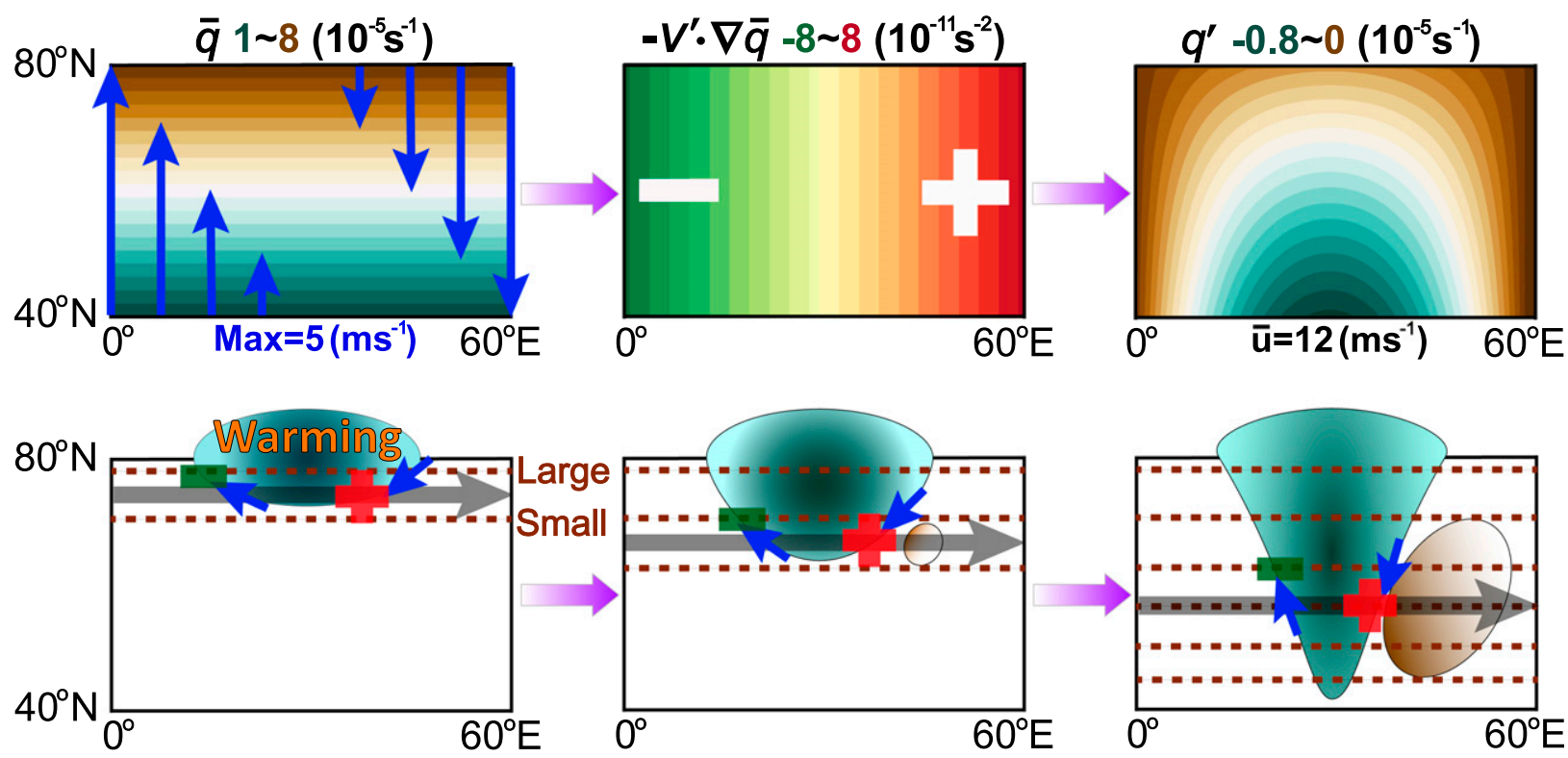

FIG. 9. (top) An ideal case of zero net horizontal PV advection (i.e., $\overline{\mathbf{V}}^{\prime} \cdot \nabla \bar{q}+\overline{\mathbf{V}} \cdot \nabla q^{\prime}=0$ ), with prescribed climatology of PV $(\bar{q})$ and wind $(\overline{\mathbf{V}})$ and change of wind $\left(\mathbf{V}^{\prime}\right)$. (top left) The prescribed $\bar{q}$ and $\mathbf{V}^{\prime}$ are shown as filled and blue arrows. Note that $\bar{q}$ is zonally uniform, and $\mathbf{V}^{\prime}$ is purely meridional (with a maximum value of $5 \mathrm{~m} \mathrm{~s}^{-1}$ ); $\overline{\mathbf{V}}$ is a uniform zonal wind $(\bar{u})$ of $12 \mathrm{~m} \mathrm{~s}^{-1}$. These prescribed values approximately correspond to the situation at $500 \mathrm{hPa}$ (Fig. 8, bottom, within the domain of approximately $40^{\circ}-80^{\circ} \mathrm{N}, 0^{\circ}-60^{\circ} \mathrm{E}$ ). (top center) Distribution of $-\mathbf{V}^{\prime} \cdot \nabla \bar{q}\left(10^{-11} \mathrm{~s}^{-2}\right)$ under prescribed values. (top right) Distribution of $q^{\prime}$ calculated from $\mathbf{V}^{\prime} \cdot \nabla \bar{q}+\overline{\mathbf{V}} \cdot \nabla q^{\prime}=0$, in which $q^{\prime}$ at $0^{\circ}$ longitude is prescribed as zero. (bottom) Schematic view of the evolution of horizontal PV advection under a situation with enhanced regional warming over the Arctic, a meridional PV gradient (larger to the north, brown dashed lines indicate isoline of PV), and purely westerly wind (gray arrow). The bottom row is based on results shown in the top row. As in the top row, the blue arrow indicates wind anomaly, "small" and "large" indicate the relative value of $\bar{q}$, and the minus and plus symbols indicate the sign of $-\mathbf{V}_{g}^{\prime} \cdot \nabla \bar{q}$. The filled symbol indicates a change in PV $\left(q^{\prime}\right)$.

to distant regions through its extended influences on circulation.

Actually, from a traditional wave view, the $500-\mathrm{hPa}$ geopotential change associated with Eurasian cooling can be connected to the anomalous stationary wave that originated from upstream regions (e.g., Sung et al. 2018; $\mathrm{Li}$ et al. 2019). As shown in Fig. 11a, two wave trains pointed to the Eurasian cooling region. One is the western branch from Europe, and the other is the southeastern branch from the eastern coast of the Eurasian continent. Given the background of climatological eastward oriented stationary wave train (Fig. 11b), the upstream wave train means enhancement of the upstream influences the area from Europe to the Eurasian cooling region (Fig. 11a), while the downstream wave train means a reduction in the downstream influences from the Eurasian cooling region. Thus, the upstream wave train from Europe may contribute to the Eurasian cooling. However, the point is that the eddy streamfunction change over European regions connects with Arctic warming as demonstrated above. Such a wave view is a particular aspect of the PV view we proposed in Figs. 9 and 10 because anomalous wave depends on the existence of PV change (Hoskins et al. 1985; Plumb 1985, 1986).

\section{Concluding remarks}

By combining PV inversion with the PV equation, this paper explored the general dynamics that could connect the Eurasian cooling with Arctic warming from the PV view. We drew a schematic view that synthetically summarized the major conclusions from this paper in Fig. 12. The major results of this paper are summarized as follows:

1) Both Arctic warming and Eurasian cooling from 1979 to 2017 occurred throughout the entire troposphere. Eurasian cooling is large at both the surface and middle troposphere (approximately $500 \mathrm{hPa}$ ), while Arctic warming is most significant in lower layers.

2) Through PV adaptation, anticyclonic circulation change is generated by negative PV change, and the negative PV change is generated by the diabatic heating effect of Arctic warming that is stronger at 


\section{$500 \mathrm{hPa}$ geopotential change $\left(\mathrm{m}^{2} \mathrm{~s}^{-2}\right)$ due to total change over \\ $\left[70^{\circ} \mathrm{N} \sim 90^{\circ} \mathrm{N}\right]$}

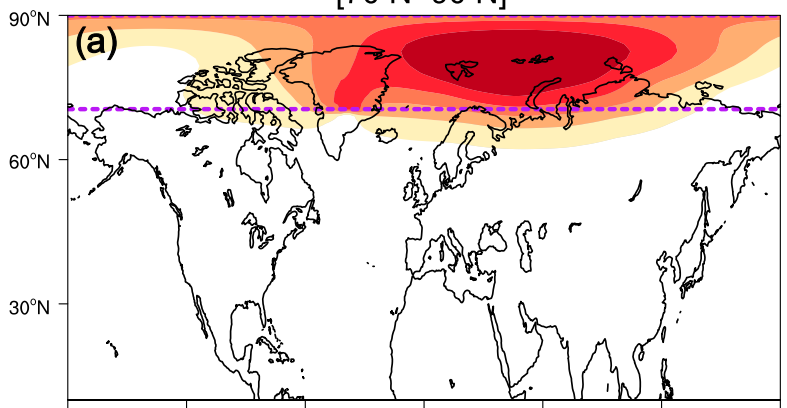

$\left[30^{\circ} \mathrm{N} \sim 70^{\circ} \mathrm{N}\right]$

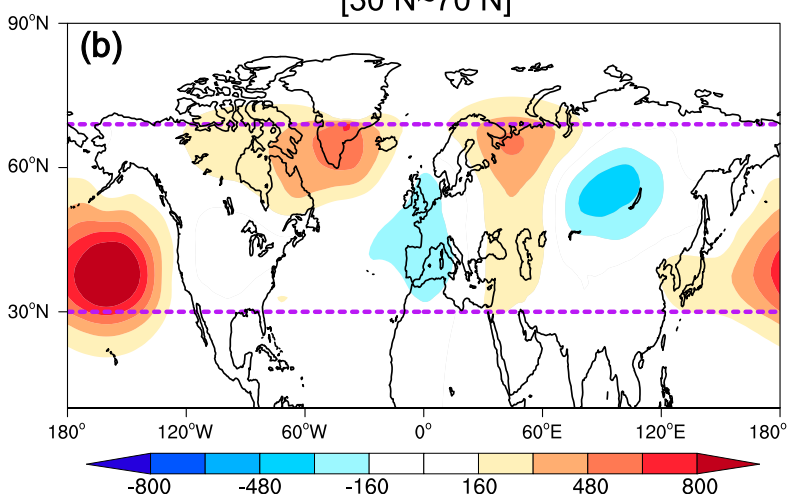

FIG. 10. Inverted 500-hPa geopotential changes $\left(\mathrm{m}^{2} \mathrm{~s}^{-2}\right)$ (linear trend multiplied the time span) from PPVI with three pieces, during the boreal winter from 1979 to 2017. The three pieces are total change over regions of (a) $70^{\circ}-90^{\circ} \mathrm{N}$ and (b) $30^{\circ}-70^{\circ} \mathrm{N}$, as well as $10^{\circ}-30^{\circ} \mathrm{N}$ (not shown). The purple dashed lines indicate the boundary of each piece. The lateral boundary conditions (geopotential change) at $90^{\circ}$ and $10^{\circ} \mathrm{N}$ are observed and zero for the $70^{\circ}-90^{\circ} \mathrm{N}$ piece, both zero for the $30^{\circ}-70^{\circ} \mathrm{N}$ piece, and zero and observed for the $10^{\circ}-30^{\circ} \mathrm{N}$ piece.

lower levels. Here, PV adaptation refers to the adaptation of PV to forcing and coherent dynamicthermodynamic adaptation to PV change.

3) Enhanced Eurasian cooling in the middle troposphere (around $500 \mathrm{hPa}$ ) is dominated by the top-down influence. Stratospheric influence on the troposphere change from 1979 to 2017 is negligible, especially for the middle and low latitudes.

4) Change in horizontal PV advection is the cause of the horizontal coupling between the Arctic and the midlatitudes. The anticyclonic circulation change associated with Arctic warming and the climatological PV gradients are essential to horizontal PV advection change.

5) Taking the vertical and horizontal couplings together, enhanced Eurasian cooling at both the surface and in the middle troposphere is affected by the
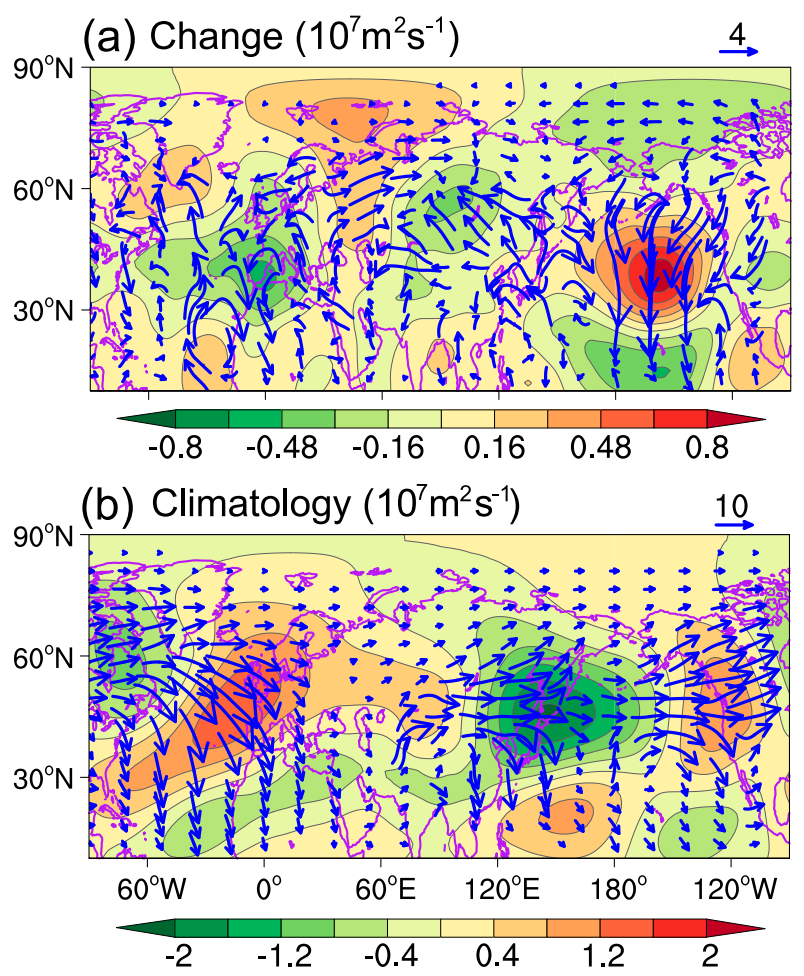

FIG. 11. (a) Changes (linear trend multiplied by the time span) in eddy (with zonal mean value removed) streamfunction (filled; $10^{7} \mathrm{~m}^{2} \mathrm{~s}^{-1}$ ) and Plumb flux (vectors; $\mathrm{m}^{2} \mathrm{~s}^{-2}$ ) at $500 \mathrm{hPa}$ for the period of 1979-2017 during boreal winter. (b) Climatology for the period of 1979-2017 corresponding to (a).

Arctic warming through PV advection and PV adaptation. Eurasian cooling at the surface and in the lower troposphere is dominated by PV advection and PV adaptation at the surface. Meanwhile, enhanced Eurasian cooling in the middle troposphere is dominated by upper-level horizontal PV advection and corresponding PV adaptation.

In summary, we demonstrated a PV view picture of the three-dimensional linkages between wintertime Eurasian cooling and Arctic warming from 1979 to 2017. The whole situation is described by using only the concept of PV adaptation and PV advection. Technically, this paper presents an example of the use of PV dynamics in the climate change realm.

In plain language, the spatial pattern and vertical structure of Arctic warming and climatological PV distribution are crucial factors that determine the linkage between midlatitude and Arctic. First, the zonal asymmetry and uneven vertical warming are crucial for a large circulation change directly corresponding to the Arctic warming. Second, the large climatological PV gradient is crucial to the southward extension of the 


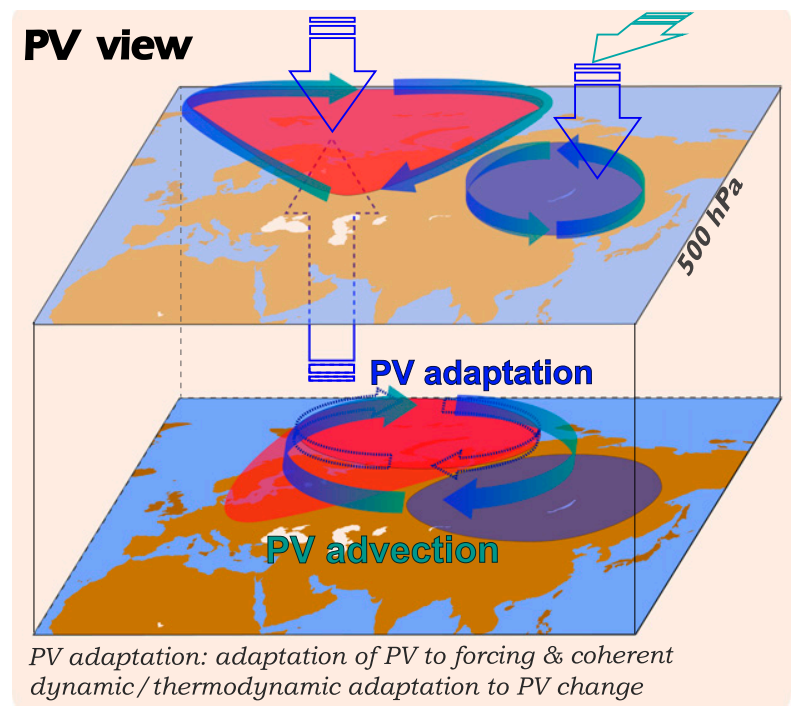

FIG. 12. Schematic view of the whole situation described in this paper. The red and blue shading indicate warming and cooling, respectively. The dashed blue arrows indicate circulation anomalies with PV adaptation but without horizontal PV advection. The mixed blue and turquoise filled arrows indicate the final circulation anomalies with both PV adaptation and PV advection. The topmost map indicates the 500-hPa level. The blue and turquoise arrows with tails indicate the direction of influences from PV adaptation and PV advection, respectively.

anticyclonic circulation change associated with Arctic warming and corresponding downstream influences on Eurasia.

Overland et al. (2016) summarized the complexity of midlatitude and Arctic connections. According to our findings, the complexity is partly due to the complexity of PV adaptation and PV advection. As we concluded above, the complexity is associated with the spatial pattern and vertical structure of Arctic warming and climatological PV distribution (Kug et al. 2015; Koenigk et al. 2016; Luo et al. 2018). Recently, D. Luo et al. (2019) further suggested the crucial role of climatological PV gradient in controlling the linkage between Arctic and midlatitude weather extremes through regulating atmospheric blocking.

Overall, our findings could be beneficial for both theoretical understanding and practical modeling. For example, attention should be paid to climatological PV distribution when performing emergent constraints on the climate model. However, it should be kept in mind that this paper only depicts the general dynamical linkages between Arctic warming and Eurasian cooling, while the Arctic warming itself can be contributed to by both anthropogenic forcing and internal climate variability (Ding et al. 2019; Mori et al. 2019). Furthermore, regarding the direct connections between sea ice and the midlatitudes, recent model-based studies suggest that sea ice has minimal influence on Eurasian cooling on both long-term and interannual time scales (Ogawa et al. 2018; Blackport et al. 2019).

Acknowledgments. We thank Joseph Egger for helpful comments. We thank three anonymous reviewers and an adjudicator for constructive and helpful comments, which were very helpful in improving our paper. We thank ECMWF for making their data available. This work is supported by the Priority Research Program of the Chinese Academy of Sciences (QYZDY-SSWDQC018) and the National Natural Science Foundation of China (41730963).

\section{APPENDIX}

\section{Step-by-Step Procedure of Piecewise PPVI}

1) To perform numerical integration, the equation must be nondimensionalized. The nondimensional form of Eq. (2) is $q^{\prime *}=C_{1} \nabla^{2} \Phi^{\prime *}+C_{2}\left(\partial \Phi^{\prime *} / \partial p^{*}\right)+$ $C_{3}\left(\partial^{2} \Phi^{\prime *} / \partial p^{* 2}\right)$, where $\Phi=\Phi_{0} \Phi^{*}, q=f_{0} q^{*}, p=p_{0} p^{*}$, $C_{1}=\Phi_{0} / f_{0}^{2} a^{2}, \quad C_{2}=(\partial / \partial p)(1 / \bar{S}), \quad C_{3}=1 / p_{0} \bar{S}, \quad \Phi_{0}=$ $10^{5} \mathrm{~m}^{2} \mathrm{~s}^{-2}$, and $p_{0}=10^{5} \mathrm{~Pa}$. Note that $p$ in $C_{2}$ is dimensional. For simplicity, the asterisk (*) is omitted hereafter in this section.

2) To solve the second-order linear partial differential equations for $\Phi^{\prime}$, we need to apply the finite-difference method. Here, we use the central differentiation method to discretize the equation. Specifically, we have $\nabla^{2} A=\left(1 / \cos ^{2} \varphi_{j}\right)\left(A_{i+1, j, k}+A_{i-1, j, k}-2 A_{i, j, k}\right) / \delta \lambda^{2}+$ $\left(A_{i, j+1, k}+A_{i, j-1, k}-2 A_{i, j, k}\right) / \delta \varphi^{2}-\tan \varphi_{j}\left[\left(A_{i, j+1, k}-\right.\right.$ $\left.\left.A_{i, j-1, k}\right) / 2 \delta \varphi\right], \quad \partial A / \partial p=\left(A_{i, j, k+1}-A_{i, j, k-1}\right) /\left(p_{k+1}-\right.$ $\left.p_{k-1}\right), \quad$ and $\quad \partial^{2} A / \partial p^{2}=\left(A_{i, j, k+1}+A_{i, j, k-1}-2 A_{i, j, k}\right) /$ $\left[\left(p_{k+1}-p_{k}\right)\left(p_{k}-p_{k-1}\right)\right]$ for arbitrary variable $A$, in which $\lambda$ and $\varphi$ are longitude and latitude, and subscripts $i, j$, and $k$ indicate the meridional, zonal, and vertical direction indexes of the three-dimensional spatial grid, respectively. Thus, six neighboring points are needed for any grid in the iteration process. The expressions used for the iteration are as follows:

$$
\begin{aligned}
\Phi_{i, j, k}^{\prime}= & {\left[-q^{\prime}+C_{4}\left(\Phi_{i+1, j, k}^{\prime}+\Phi_{i-1, j, k}^{\prime}\right)+C_{5} \Phi_{i, j+1, k}^{\prime}\right.} \\
& \left.+C_{6} \Phi_{i, j-1, k}^{\prime}+C_{7} \Phi_{i, j, k+1}^{\prime} C_{8} \Phi_{i, j, k-1}^{\prime}\right] / C_{9},
\end{aligned}
$$

where $C_{4}=C_{1} /\left[\left(\cos ^{2} \varphi_{j}\right)\left(\delta \lambda^{2}\right)\right], \quad C_{5}=C_{1}\left\{1 / \delta \varphi^{2}-\right.$ $\left.\left[\tan \varphi_{j} /(2 \delta \varphi)\right]\right\}, \quad C_{6}=C_{1}\left\{1 / \delta \varphi^{2}+\left[\tan \varphi_{j} /(2 \delta \varphi)\right]\right\}$, $C_{7}=C_{2} /\left(p_{k+1}-p_{k-1}\right)+C_{3} /\left[\left(p_{k+1}-p_{k}\right)\left(p_{k}-p_{k-1}\right)\right]$, $C_{8}=C_{3} /\left[\left(p_{\mathrm{k}+1}-p_{\mathrm{k}}\right)\left(p_{\mathrm{k}}-p_{\mathrm{k}-1}\right)\right]-C_{2} /\left(p_{\mathrm{k}+1}-p_{\mathrm{k}-1}\right)$, 


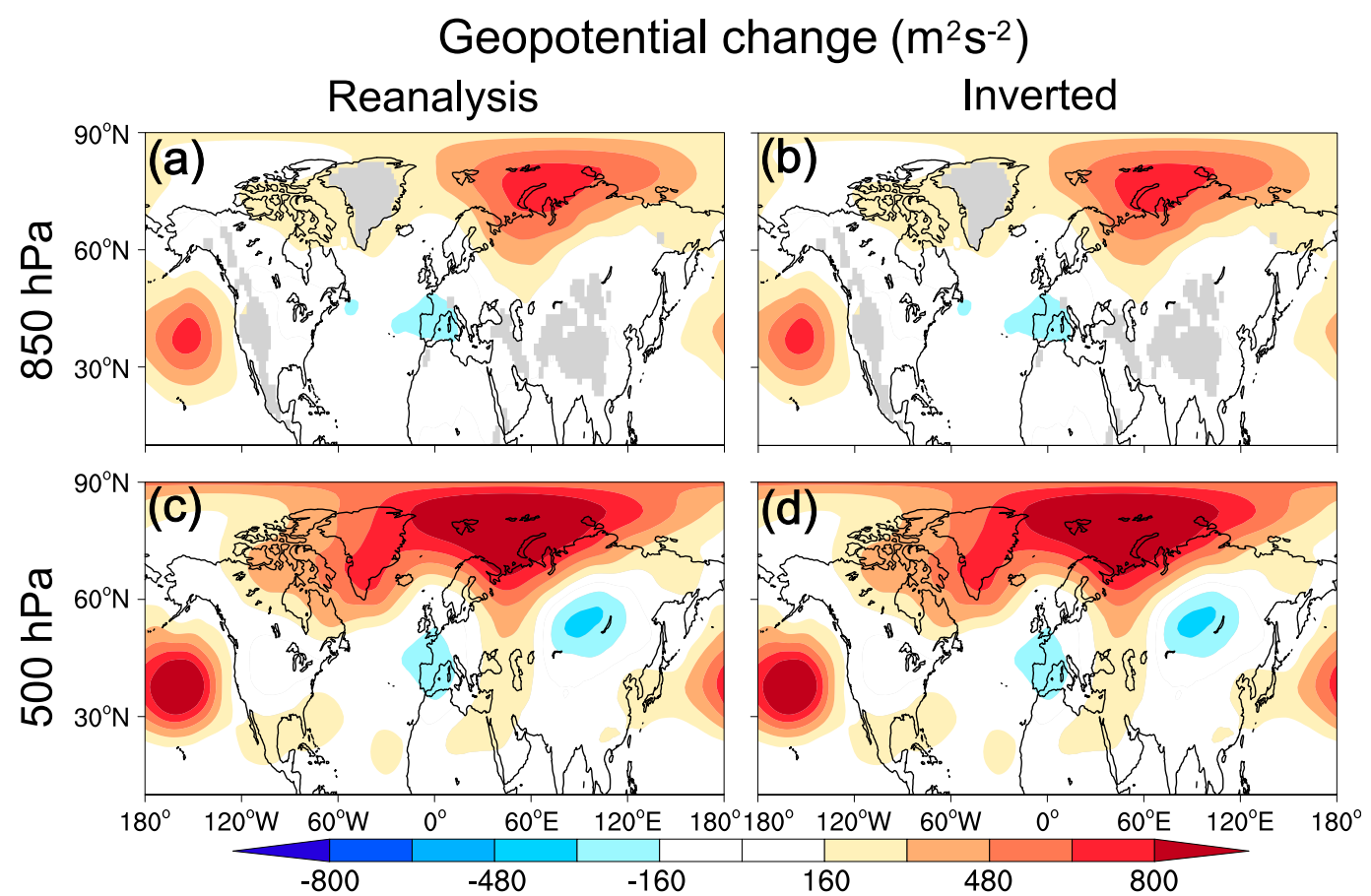

FIG. A1. Geopotential changes $\left(\mathrm{m}^{2} \mathrm{~s}^{-2}\right)$ (linear trend multiplied by the time span) during boreal winter of 19792017. Results are shown (a),(c) directly from reanalysis data and (b),(d) from PV inversion, for the (top) 850- and (bottom) $500-\mathrm{hPa}$ levels. The domain for performing inversion is poleward of $10^{\circ} \mathrm{N}$. The absolute values of the maximum discrepancies between (a) and (b) and between (c) and (d) are 6.6 and $2.4 \mathrm{~m}^{2} \mathrm{~s}^{-2}$, respectively.

$C_{9}=2 C_{1} /\left[\left(\cos ^{2} \varphi_{j}\right)\left(\delta \lambda^{2}\right)\right]+2 C_{1} / \delta \varphi^{2}+2 C_{3} /\left[\left(p_{k+1}-p_{k}\right)\right.$ $\left.\left(p_{k}-p_{k-1}\right)\right]$, and $\delta \lambda$ and $\delta \varphi$ are longitude and latitude intervals, respectively, for an equally divided horizontal rectangular grid. The successive overrelaxation method is adopted for the final iteration:

$$
\begin{aligned}
\Phi_{i, j, k}^{\prime m+1}= & (1-\omega) \Phi_{i, j, k}^{\prime m}+\omega\left[-q^{\prime}+C_{4}\left(\Phi_{i+1, j, k}^{\prime}+\Phi_{i-1, j, k}^{\prime}\right)\right. \\
& +C_{5} \Phi_{i, j+1, k}^{\prime}+C_{6} \Phi_{i, j-1, k}^{\prime}+C_{7} \Phi_{i, j, k+1}^{\prime} \\
& \left.+C_{8} \Phi_{i, j, k-1}^{\prime}\right] / C_{9}
\end{aligned}
$$

where $m$ indicates the round of integration and $\omega$ is the weight for successive overrelaxation, with a value of 1.6 in this study.

3) Boundary conditions for the geopotential are needed for numerical solution. The lateral and horizontal boundary conditions are the Dirichlet and Neumann conditions, respectively. For simplicity, the target area within a relatively large rectangular domain is commonly confined and outlined by latitude and longitude lines. Here, we chose the domain northward of $10^{\circ} \mathrm{N}$, so that there are no boundaries on the east and west sides. Thus, the only lateral boundaries are at the North Pole and $10^{\circ} \mathrm{N}$. We chose the geo- potential at the southern boundary to be zero because it is far from our target zone (Hartley et al. 1998; Davis 1992). However, we may not make the same choice for the northern boundary because we are exploring extratropical aspects. In this sense, we first obtain the

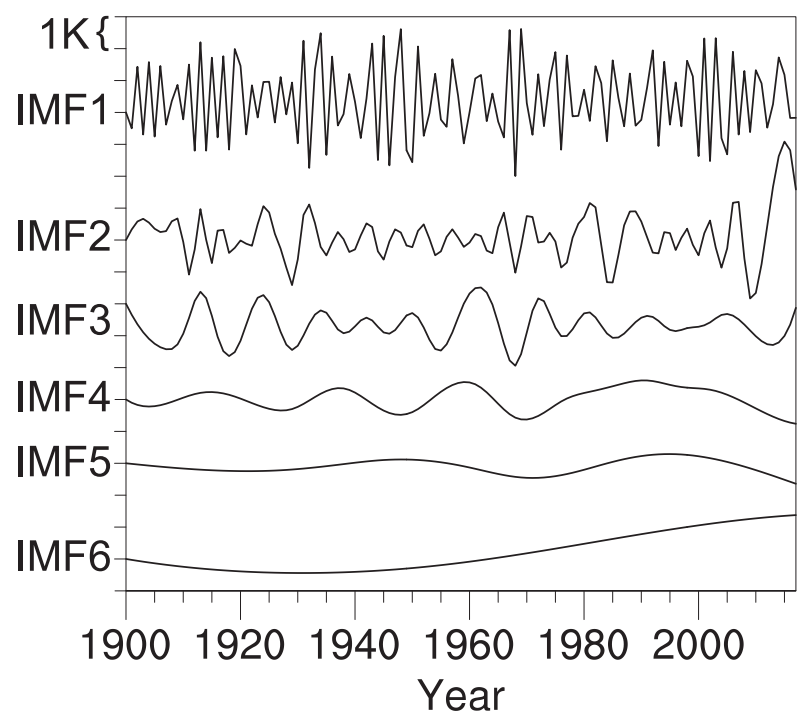

FIG. A2. IMFs 1-6 of EEMD corresponding to Fig. 1b. 
inverted geopotential from the piecewise PPVI using the zero boundary condition at the North Pole. Second, the boundary condition is given by portioning the total geopotential from reanalysis at the North Pole to each piece based on the percentage. This percentage is calculated as the mean geopotential north of $80^{\circ} \mathrm{N}$, except at the North Pole, in each piece relative to the total geopotential perturbation. Finally, the piecewise inversion is performed again by using the new boundary conditions at the North Pole. In fact, all our conclusions are not influenced even using a simple zero north boundary. The horizontal boundary conditions are given by using the hydrostatic balance $\partial \Phi / \partial p=-\alpha$ at both the surface and the top.

4) Eventually, the iteration is performed according to Eq. (A1) for the interior layers. Meanwhile, the iteration at the surface and top boundaries should be performed according to Eq. (A2) with the given boundary conditions.

$$
\begin{aligned}
\Phi_{i, j, k}^{\prime m+1}= & (1-\omega) \Phi_{i, j, k}^{\prime m}+\omega\left[-q^{\prime}+C_{4}\left(\Phi_{i+1, j, k}^{\prime}+\Phi_{i-1, j, k}^{\prime}\right)\right. \\
& \left.+C_{5} \Phi_{i, j+1, k}^{\prime}+C_{6} \Phi_{i, j-1, k}^{\prime}+C_{10}\right] / C_{11}
\end{aligned}
$$

where $\mathrm{C}_{10}=-C_{2} \alpha^{\prime}-C_{3}\left(\partial \alpha^{\prime} / \partial p\right)$ and $C_{11}=2 C_{1} /$ $\left[\left(\cos ^{2} \varphi_{j}\right)\left(\delta \lambda^{2}\right)\right]+2 C_{1} / \delta \varphi^{2}$. The iteration is terminated when the absolute value of geopotential differences between two iterations is less than $1 \mathrm{~m}^{2} \mathrm{~s}^{-2}$ in all threedimensional grids.

The performance of PPVI must be assessed before exploring the results from PPVI. To test the accuracy of PPVI, we perform a simple inversion regarding the total PV change during the boreal winter from 1979 to 2017 over the domain northward of $10^{\circ} \mathrm{N}$. Figure A1 shows the original and inverted geopotential changes both at the $850-$ and $500-\mathrm{hPa}$ levels. Geopotential changes at both 850 and $500 \mathrm{hPa}$ from PPVI are identical to the original results directly from reanalysis. Thus, our PPVI procedure is accurate. Figure 2 shows the six IMFs obtained by EEMD that was performed on the gray line in Fig. 1b.

\section{REFERENCES}

Blackport, R., J. A. Screen, K. van der Wiel, and R. Bintanja, 2019: Minimal influence of reduced Arctic sea ice on coincident cold winters in mid-latitudes. Nat. Climate Change, 9, 697-704, https://doi.org/10.1038/s41558-019-0551-4.

Charney, J. G., and M. Stern, 1962: On the stability of internal baroclinic jets in a rotating atmosphere. J. Atmos. Sci. 19, 159-172, https://doi.org/10.1175/1520-0469(1962)019<0159:OTSOIB > 2.0.CO;2.
Cohen, J., and Coauthors, 2014: Recent Arctic amplification and extreme mid-latitude weather. Nat. Geosci., 7, 627-637, https:// doi.org/10.1038/ngeo2234.

_ , and Coauthors, 2018: Arctic change and possible influence on mid-latitude climate and weather. US CLIVAR Rep. 2018-1, 41 pp., https://doi.org/10.5065/D6TH8KGW.

Coumou, D., G. Di Capua, S. Vavrus, L. Wang, and S. Wang, 2018: The influence of Arctic amplification on mid-latitude summer circulation. Nat. Commun., 9, 2959, https://doi.org/10.1038/ s41467-018-05256-8.

Dai, A., J. C. Fyfe, S.-P. Xie, and X. Dai, 2015: Decadal modulation of global surface temperature by internal climate variability. Nat. Climate Change, 5, 555-559, https://doi.org/10.1038/nclimate2605.

Davis, C. A., 1992: Piecewise potential vorticity inversion. J. Atmos. Sci., 49, 1397-1411, https://doi.org/10.1175/1520-0469(1992)049<1397: PPVI $>2.0 . \mathrm{CO} ; 2$.

_ , and K. A. Emanuel, 1991: Potential vorticity diagnostics of cyclogenesis. Mon. Wea. Rev., 119, 1929-1953, https://doi.org/ 10.1175/1520-0493(1991)119<1929:PVDOC>2.0.CO;2.

Dee, D. P., and Coauthors, 2011: The ERA-Interim reanalysis: Configuration and performance of the data assimilation system. Quart. J. Roy. Meteor. Soc., 137, 553-597, https://doi.org/ 10.1002/qj.828.

Di Capua, G., and D. Coumou, 2016: Changes in meandering of the Northern Hemisphere circulation. Environ. Res. Lett., 11, 094028, https://doi.org/10.1088/1748-9326/11/9/094028.

Ding, Q., and Coauthors, 2019: Fingerprints of internal drivers of Arctic sea ice loss in observations and model simulations. Nat. Geosci., 12, 28-33, https://doi.org/10.1038/s41561-018-0256-8.

Easterling, D. R., and M. F. Wehner, 2009: Is the climate warming or cooling? Geophys. Res. Lett., 36, L08706, https://doi.org/ 10.1029/2009GL037810.

Egger, J., 2008: Piecewise potential vorticity inversion: Elementary tests. J. Atmos. Sci., 65, 2015-2024, https://doi.org/10.1175/ 2007JAS2564.1.

— piecewise potential vorticity inversion. J. Atmos. Sci., 75, 875883, https://doi.org/10.1175/JAS-D-17-0039.1.

— vorticity fluxes: Climatology and impermeability. J. Atmos. Sci., 72, 3257-3267, https://doi.org/10.1175/JAS-D-14-0196.1.

,-- , and,- 2017 : Inversion of potential vorticity density. J. Atmos. Sci., 74, 801-807, https://doi.org/10.1175/JAS-D-16-0133.1.

Ertel, H., 1942: Ein neuer hydrodynamischer Wirbelsatz. Meteor. Z., 59, 277-281.

Francis, J. A., and S. J. Vavrus, 2012: Evidence linking Arctic amplification to extreme weather in mid-latitudes. Geophys. Res. Lett., 39, L06801, https://doi.org/10.1029/2012GL051000.

$\longrightarrow$, and — 2015: Evidence for a wavier jet stream in response to rapid Arctic warming. Environ. Res. Lett., 10, 014005 , https://doi.org/10.1088/1748-9326/10/1/014005.

Gu, S., Y. Zhang, Q. Wu, and X. Yang, 2018: The linkage between Arctic sea ice and midlatitude weather: In the perspective of energy. J. Geophys. Res. Atmos., 123, 11536-11550, https:// doi.org/10.1029/2018JD028743.

Hartley, D. E., J. T. Villarin, R. X. Black, and C. A. Davis, 1998: A new perspective on the dynamical link between the stratosphere and troposphere. Nature, 391, 471-474, https://doi.org/ 10.1038/35112.

Held, I. M., 2013: Climate science: The cause of the pause. Nature, 501, 318-319, https://doi.org/10.1038/501318a.

Holton, J. R., and G. J. Hakim, 2013: An Introduction to Dynamic Meteorology. Academic Press, 532 pp. 
Hoskins, B. J., M. E. McIntyre, and A. W. Robertson, 1985: On the use and significance of isentropic potential vorticity maps. Quart. J. Roy. Meteor. Soc., 111, 877-946, https://doi.org/ 10.1002/qj.49711147002.

Huang, J., Y. Xie, X. Guan, D. Li, and F. Ji, 2017: The dynamics of the warming hiatus over the Northern Hemisphere. Climate Dyn., 48, 429-446, https://doi.org/10.1007/s00382-016-3085-8.

Ji, F., Z. Wu, J. Huang, and E. P. Chassignet, 2014: Evolution of land surface air temperature trend. Nat. Climate Change, $\mathbf{4}$ 462-466, https://doi.org/10.1038/nclimate2223.

Koenigk, T., M. Caian, G. Nikulin, and S. Schimanke, 2016: Regional Arctic sea ice variations as predictor for winter climate conditions. Climate Dyn., 46, 317-337, https://doi.org/ 10.1007/s00382-015-2586-1.

Kosaka, Y., and S.-P. Xie, 2013: Recent global-warming hiatus tied to equatorial Pacific surface cooling. Nature, 501, 403-407, https://doi.org/10.1038/nature12534.

Kug, J.-S., J.-H. Jeong, Y.-S. Jang, B.-M. Kim, C. K. Folland, S.-K. Min, and S.-W. Son, 2015: Two distinct influences of Arctic warming on cold winters over North America and East Asia. Nat. Geosci., 8, 759-762, https://doi.org/10.1038/ngeo2517.

Li, X., Z. Wu, and Y. Li, 2019: A link of China warming hiatus with the winter sea ice loss in Barents-Kara Seas. Climate Dyn., 53, 2625-2642, https://doi.org/10.1007/s00382-019-04645-z.

Luo, B., L. Wu, D. Luo, A. Dai, and I. Simmonds, 2019: The winter midlatitude-Arctic interaction: Effects of North Atlantic SST and high-latitude blocking on Arctic sea ice and Eurasian cooling. Climate Dyn., 52, 2981-3004, https://doi.org/10.1007/ s00382-018-4301-5.

Luo, D., Y. Xiao, Y. Diao, A. Dai, C. L. Franzke, and I. Simmonds, 2016: Impact of Ural blocking on winter warm Arctic-cold Eurasian anomalies. Part II: The link to the North Atlantic Oscillation. J. Climate, 29, 3949-3971, https://doi.org/10.1175/ JCLI-D-15-0612.1.

_, Y. Chen, A. Dai, M. Mu, R. Zhang, and I. Simmonds, 2017a: Winter Eurasian cooling linked with the Atlantic Multidecadal Oscillation. Environ. Res. Lett., 12, 125002, https://doi.org/ 10.1088/1748-9326/aa8de8.

_ - Y. Yao, A. Dai, I. Simmonds, and L. Zhong, 2017b: Increased quasi stationarity and persistence of winter Ural blocking and Eurasian extreme cold events in response to Arctic warming. Part II: A theoretical explanation. J. Climate, 30, 3569-3587, https://doi.org/10.1175/JCLI-D-16-0262.1.

—, X. Chen, A. Dai, and I. Simmonds, 2018: Changes in atmospheric blocking circulations linked with winter Arctic warming: A new perspective. J. Climate, 31, 7661-7678, https://doi.org/ 10.1175/JCLI-D-18-0040.1.

, - _ J. E. Overland, I. Simmonds, Y. Wu, and P. Zhang, 2019: Weakened potential vorticity barrier linked to recent winter Arctic sea ice loss and midlatitude cold extremes. J. Climate, 32, 4235-4261, https://doi.org/10.1175/JCLI-D-180449.1.

Mori, M., Y. Kosaka, M. Watanabe, H. Nakamura, and M. Kimoto, 2019: A reconciled estimate of the influence of Arctic sea-ice loss on recent Eurasian cooling. Nat. Climate Change, 9, 123129, https://doi.org/10.1038/s41558-018-0379-3.

Ogawa, F., and Coauthors, 2018: Evaluating impacts of recent Arctic sea ice loss on the Northern Hemisphere winter climate change. Geophys. Res. Lett., 45, 3255-3263, https://doi.org/ 10.1002/2017GL076502.

Overland, J. E., and Coauthors, 2016: Nonlinear response of midlatitude weather to the changing Arctic. Nat. Climate Change, 6, 992-999, https://doi.org/10.1038/nclimate3121.
Plumb, R. A., 1985: On the three-dimensional propagation of stationary waves. J. Atmos. Sci., 42, 217-229, https://doi.org/ 10.1175/1520-0469(1985)042<0217:OTTDPO > 2.0.CO;2.

- 1986: Three-dimensional propagation of transient quasigeostrophic eddies and its relationship with the eddy forcing of the time-mean flow. J. Atmos. Sci., 43, 1657-1678, https://doi.org/ 10.1175/1520-0469(1986)043<1657:TDPOTQ>2.0.CO;2.

Schneider, T., I. M. Held, and S. T. Garner, 2003: Boundary effects in potential vorticity dynamics. J. Atmos. Sci., 60, 1024-1040, https://doi.org/10.1175/1520-0469(2003)60<1024:BEIPVD> 2.0.CO;2.

Screen, J. A., and I. Simmonds, 2010: The central role of diminishing sea ice in recent Arctic temperature amplification. Nature, 464, 1334-1337, https://doi.org/10.1038/nature09051. , and - 2013: Caution needed when linking weather extremes to amplified planetary waves. Proc. Natl. Acad. Sci. USA, 110, E2327, https://doi.org/10.1073/pnas.1304867110.

- and _ 2014: Amplified mid-latitude planetary waves favour particular regional weather extremes. Nat. Climate Change, 4, 704-709, https://doi.org/10.1038/nclimate2271.

_ T. J. Bracegirdle, and I. Simmonds, 2018: Polar climate change as manifest in atmospheric circulation. Curr. Climate Change Rep., 4, 383-395, https://doi.org/10.1007/s40641-018-0111-4.

Shepherd, T. G., 2016: Effects of a warming Arctic. Science, 353, 989-990, https://doi.org/10.1126/science.aag2349.

Smagorinsky, J., 1953: The dynamical influence of large-scale heat sources and sinks on the quasi-stationary mean motions of the atmosphere. Quart. J. Roy. Meteor. Soc., 79, 342-366, https:// doi.org/10.1002/qj.49707934103.

Smith, D., and Coauthors, 2019: The Polar Amplification Model Intercomparison Project (PAMIP) contribution to CMIP6: Investigating the causes and consequences of polar amplification. Geosci. Model Dev., 12, 1139-1164, https://doi.org/ 10.5194/gmd-12-1139-2019.

Spengler, T., and J. Egger, 2012: Potential vorticity attribution and causality. J. Atmos. Sci., 69, 2600-2607, https://doi.org/10.1175/ JAS-D-11-0313.1.

Steinman, B. A., M. E. Mann, and S. K. Miller, 2015: Atlantic and Pacific multidecadal oscillations and Northern Hemisphere temperatures. Science, 347, 988-991, https://doi.org/10.1126/ science. 1257856.

Stouffer, R. J., and S. Manabe, 2017: Assessing temperature pattern projections made in 1989. Nat. Climate Change, 7, 163165, https://doi.org/10.1038/nclimate3224.

Sung, M., S. Kim, B. Kim, and Y. Choi, 2018: Interdecadal variability of the warm Arctic and cold Eurasia pattern and its North Atlantic origin. J. Climate, 31, 5793-5810, https:// doi.org/10.1175/JCLI-D-17-0562.1.

Trenberth, K. E., 2015: Has there been a hiatus? Science, 349, 691692, https://doi.org/10.1126/science.aac9225.

Wallace, J. M., Q. Fu, B. V. Smoliak, P. Lin, and C. M. Johanson, 2012: Simulated versus observed patterns of warming over the extratropical Northern Hemisphere continents during the cold season. Proc. Natl. Acad. Sci. USA, 109, 14337-14342, https:// doi.org/10.1073/pnas.1204875109.

Wegmann, M., Y. J. Orsolini, and O. Zolina, 2018: Warm Arcticcold Siberia: Comparing the recent and the early 20th-century Arctic warmings. Environ. Res. Lett., 13, 025009, https:// doi.org/10.1088/1748-9326/aaa0b7.

Wu, Z., N. E. Huang, J. M. Wallace, B. V. Smoliak, and X. Chen, 2011: On the time-varying trend in global-mean surface temperature. Climate Dyn., 37, 759-773, https://doi.org/10.1007/ s00382-011-1128-8. 
Xie, Y., J. Huang, and Y. Ming, 2019: Robust regional warming amplifications directly following the anthropogenic emission. Earth's Future, 7, 363-369, https://doi.org/10.1029/2018EF001068.

Yang, X.-Y., X. Yuan, and M. Ting, 2016: Dynamical link between the Barents-Kara sea ice and the Arctic Oscillation. J. Climate, 29, 5103-5122, https://doi.org/10.1175/JCLI-D-15-0669.1.

Yang, Z., W. Huang, B. Wang, R. Chen, J. S. Wright, and W. Ma, 2018: Possible mechanisms for four regimes associated with cold events over East Asia. Climate Dyn., 51, 35-56, https:// doi.org/10.1007/s00382-017-3905-5.

Yao, Y., D. Luo, A. Dai, and I. Simmonds, 2017: Increased quasi stationarity and persistence of winter Ural blocking and Eurasian extreme cold events in response to Arctic warming. Part I: Insights from observational analyses. J. Climate, 30, 3549-3568, https://doi.org/10.1175/JCLI-D-16-0261.1.
Ye, K., T. Jung, and T. Semmler, 2018: The influences of the Arctic troposphere on the midlatitude climate variability and the recent Eurasian cooling. J. Geophys. Res. Atmos., 123, 10162 10 184, https://doi.org/10.1029/2018JD028980.

Yeh, T.-C., and P.-C. Chu, 1958: Some Fundamental Problems of the General Circulation of the Atmosphere (in Chinese). Science Press, 159 pp.

Zhang, P., Y. Wu, I. R. Simpson, K. L. Smith, X. Zhang, B. De, and P. Callaghan, 2018: A stratospheric pathway linking a colder Siberia to Barents-Kara Sea sea ice loss. Sci. Adv., 4, eaat6025, https://doi.org/10.1126/sciadv.aat6025.

Zhao, B., G. Wu, and X. Yao, 2007: Potential vorticity structure and inversion of the cyclogenesis over the Yangtze River and Huaihe River valleys. Adv. Atmos. Sci., 24, 44-54, https:// doi.org/10.1007/s00376-007-0044-7. 